\title{
The impact of the COVID-19 pandemic on self-harm and
}

\section{suicidal behaviour: a living systematic review [version 1; peer}

\section{review: 1 approved, 2 approved with reservations]}

\author{
Ann John (iD1,2*, Chukwudi Okolie (iD)1,2, Emily Eyles (i)3,4, Roger T. Webb5,6, \\ Lena Schmidt (D) 4, Luke A. McGuinness (D) 4, Babatunde K. Olorisade (D)4, \\ Ella Arensman7, Keith Hawton (1) 8,9, Nav Kapur5,6,10, Paul Moran4,11, \\ Rory C. O'Connor ${ }^{12}$, Siobhan O'Neill13, Julian P.T. Higgins ${ }^{3,4,11^{*}}$, David Gunnell ${ }^{4,11^{*}}$
}

\footnotetext{
${ }_{1}^{1}$ Population Psychiatry, Suicide and Informatics, Swansea University, Swansea, UK

2Public Health Wales NHS Trust, Swansea, UK

${ }^{3}$ National Institute for Health Research Applied Research Collaboration West (NIHR ARC West) at University Hospitals Bristol NHS Foundation Trust, Bristol, UK

${ }^{4}$ Population Health Sciences, University of Bristol, Bristol, UK

${ }^{5}$ Division of Psychology and Mental Health, University of Manchester, Manchester, UK

${ }^{6}$ NIHR Greater Manchester Patient Safety Translational Research Centre, Manchester, UK

${ }^{7}$ School of Public Health and National Suicide Research Foundation, University College Cork, Cork, Ireland

${ }^{8}$ University Department of Psychiatry, Centre for Suicide Research, University of Oxford, Oxford, UK

${ }^{9}$ Oxford Health NHS Foundation Trust, Oxford, UK

${ }^{10}$ Greater Manchester Mental Health NHS Foundation Trust, Manchester, UK

${ }^{11}$ National Institute for Health Research Biomedical Research Centre at the University Hospitals Bristol NHS Foundation Trust and the University of Bristol, Bristol, UK

12Institute of Health \& Wellbeing, University of Glasgow, Glasgow, UK

${ }^{13}$ School of Psychology, Ulster University, Coleraine, UK

* Equal contributors
}

V1 First published: $04 \operatorname{Sep} 2020$, 9:1097

https://doi.org/10.12688/f1000research.25522.1

Latest published: 17 Jun 2021, 9:1097

https://doi.org/10.12688/f1000research.25522.2

\section{Abstract}

Background: The COVID-19 pandemic has caused morbidity and mortality, as well as, widespread disruption to people's lives and livelihoods around the world. Given the health and economic threats posed by the pandemic to the global community, there are concerns that rates of suicide and suicidal behaviour may rise during and in its aftermath. Our living systematic review (LSR) focuses on suicide prevention in relation to COVID-19, with this iteration synthesising relevant evidence up to June $7^{\text {th }} 2020$.

Method: Automated daily searches feed into a web-based database with screening and data extraction functionalities. Eligibility criteria include incidence/prevalence of suicidal behaviour, exposure-outcome relationships and effects of interventions in relation to the COVID-19 pandemic. Outcomes of interest are suicide, self-harm or attempted

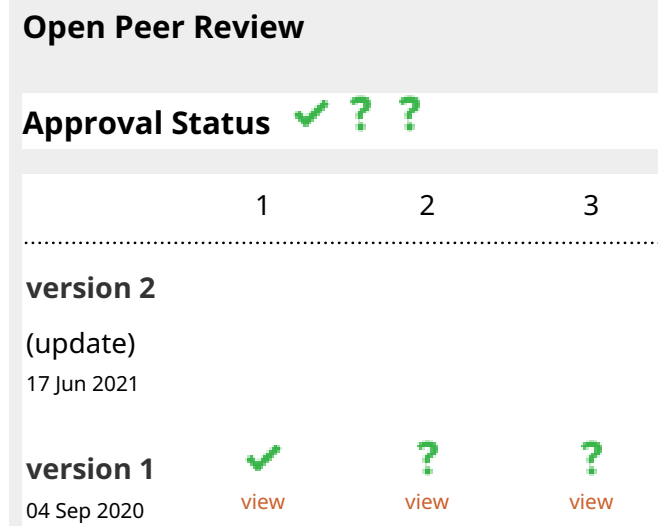

1. Lakshmi Vijayakumar (D), VHS SNEHA

(Suicide Prevention Agency), Chennai, India

2. Kimberly A Van Orden (D), University of 
suicide and suicidal thoughts. No restrictions are placed on language or study type, except for single-person case reports.

Results: Searches identified 2070 articles, 29 (28 studies) met our inclusion criteria, of which 14 articles were research letters or preprints awaiting peer review. All articles reported observational data: 12 cross-sectional; eight case series; five modelling; and three service utilisation studies. No studies reported on changes in rates of suicidal behaviour. Case series were largely drawn from news reporting in low/middle income countries and factors associated with suicide included fear of infection, social isolation and economic concerns. Conclusions: A marked improvement in the quality of design, methods, and reporting in future studies is needed. There is thus far no clear evidence of an increase in suicide, self-harm, suicidal behaviour, or suicidal thoughts associated with the pandemic. However, suicide data are challenging to collect in real time and economic effects are evolving. Our LSR will provide a regular synthesis of the most up-to-date research evidence to guide public health and clinical policy to mitigate the impact of COVID-19 on suicide.

PROSPERO registration: CRD42020183326 01/05/2020

Keywords

COVID-19, Living systematic review, Suicide; Attempted suicide, Selfharm, Suicidal thoughts

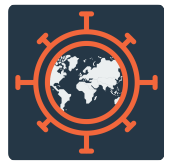

This article is included in the Emerging Diseases and Outbreaks gateway.

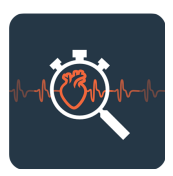

This article is included in the Living Evidence collection.
Rochester Medical Center, Rochester, USA

3. Gonzalo Martinez-Ales (iD), Columbia

University, New York, USA

Any reports and responses or comments on the article can be found at the end of the article. 


\section{Corresponding author: Ann John (a.john@swansea.ac.uk)}

Author roles: John A: Conceptualization, Investigation, Methodology, Project Administration, Supervision, Writing - Original Draft Preparation, Writing - Review \& Editing; Okolie C: Data Curation, Investigation, Writing - Original Draft Preparation, Writing - Review \& Editing; Eyles E: Data Curation, Investigation, Writing - Original Draft Preparation, Writing - Review \& Editing; Webb RT: Investigation, Writing - Review \& Editing; Schmidt L: Data Curation, Methodology, Software, Visualization, Writing - Original Draft Preparation, Writing - Review \& Editing; McGuinness LA: Data Curation, Methodology, Resources, Software, Writing - Review \& Editing; Olorisade BK: Data Curation, Methodology, Writing - Review \& Editing; Arensman E: Writing - Review \& Editing; Hawton K: Writing - Review \& Editing; Kapur N: Writing - Review \& Editing; Moran P: Writing - Review \& Editing; O'Connor RC: Writing - Review \& Editing; O'Neill S: Writing Review \& Editing; Higgins JPT: Conceptualization, Methodology, Project Administration, Supervision, Writing - Original Draft Preparation, Writing - Review \& Editing; Gunnell D: Conceptualization, Investigation, Project Administration, Supervision, Writing Original Draft Preparation, Writing - Review \& Editing

Competing interests: DG: member of the Department of Health and Social Care (England) National Suicide Prevention Strategy Advisory Group. DG has grants from the National Institute for Health Research (NIHR) outside the submitted work and is a member of Samaritans Policy and Research Committee and Movember's Global Advisory Committee. Al: chair of the National Advisory Group on Suicide and Self-harm Prevention to Welsh Government and is national lead on suicide prevention for Public Health Wales. She reports grants from Medical Research Council (MRC) and MQ KH: member of the Department of Health and Social Care (England) National Suicide Prevention Strategy Advisory Group. He reports grants for DHSC and the Global Challenges Research Fund. NK: member of the Department of Health and Social Care (England) National Suicide Prevention Strategy Advisory Group and sits on committees for the National Institute for Health and Care Excellence to develop clinical guidelines for depression and self-harm. He reports grants outside the submitted work from NIHR, DHSC, and the Health Care Quality Improvement Partnership.

Grant information: This work was supported by Swansea University and the University of Bristol. DG, BKO, JPTH are supported by the NIHR Bristol Biomedical Research Centre [IS-BRC-1215-20011]. JPTH and EE are suported by the NIHR Applied Research Collaboration West. LAMcG is by the NIHR through a NIHR Doctoral Research Fellowship [DRF-2018-11-ST2-048]. LS is supported by the NIHR through a NIHR Systematic Reviews Fellowship [RM-SR-2017-09-028]. AJ and CO are supported by the Swansea University Cochrane Satellite for Suicide and Self-Harm Prevention. AJ is supported by the National Centre for Mental Health [HCRW-CA04] NK and RW are supported by the NIHR Greater Manchester Patient Safety Translational Research Centre [PSTRC-2016-003].

The funders had no role in study design, data collection and analysis, decision to publish, or preparation of the manuscript.

Copyright: $\odot 2020$ John A et al. This is an open access article distributed under the terms of the Creative Commons Attribution License, which permits unrestricted use, distribution, and reproduction in any medium, provided the original work is properly cited.

How to cite this article: John A, Okolie C, Eyles E et al. The impact of the COVID-19 pandemic on self-harm and suicidal behaviour: a living systematic review [version 1; peer review: 1 approved, 2 approved with reservations] F1000Research 2020, 9:1097 https://doi.org/10.12688/f1000research.25522.1

First published: 04 Sep 2020, 9:1097 https://doi.org/10.12688/f1000research.25522.1 


\section{Introduction}

The COVID-19 pandemic is causing widespread societal disruption and loss of life globally. By the end of June 2020 over 10 million people had been infected and over 500,000 had died (Worldometer, 2020). There are concerns about the impact of the pandemic on population mental health (Holmes et al., 2020). These stem from the impact of the virus itself on people infected, as well as front-line workers caring for them (Kisely et al., 2020), and on population mental health from the public health measures that have been implemented to minimise the spread of the virus - in particular physical distancing, leading to social isolation, disruption of businesses, services and education and threats to peoples' livelihoods. Physical distancing measures have resulted in substantial rises in unemployment, falls in GDP and concerns that many nations will enter a prolonged period of deep economic recession.

There are concerns that suicide and self-harm rates may rise during and in the aftermath of the pandemic (Gunnell et al., 2020; Reger et al., 2020). Time-series modelling indicated that the 1918-20 Spanish Flu pandemic, which caused well over 20 million deaths worldwide, led to a modest rise in the national suicide rate in the USA (Johnson \& Mueller, 2002; Wasserman, 1992). Likewise, there is evidence that suicide rates increased briefly amongst people aged over 65 years in Hong Kong during the 2003 SARS epidemic, predominantly amongst those with more severe physical illness and physical dependency (Cheung et al., 2008).

The current context is, however, very different from previous epidemics and pandemics. The 2003 SARS epidemic was restricted to relatively few countries. Furthermore, during the 100-year period since the 1918-20 influenza pandemic, global and national health systems have improved, international travel and the speed of communication of information (and disinformation) have increased, antibiotics are available to treat secondary infection, and national economies have become more inter-dependent. The availability of the internet and technological advancement has made it far easier for people to communicate and engage in home working and home schooling. However, there are marked social inequalities in relation to access to technology and ability to stay safe and continue to work, within and between countries. Public health policies and responses, and the degree of access to technology to facilitate online clinical assessments and treatments differ greatly between countries.

Key concerns in relation to suicide prevention during the pandemic include: uncertainty regarding how best to assess and support people with suicidal thoughts and behaviours, whilst maintaining physical distancing; people who have attempted suicide may not attend hospitals because they are worried about contracting COVID-19 or being a burden on the healthcare system at this time; diminished access to community-based support; exposure to traumatic experiences; and an economic recession may have an adverse impact on suicide rates (Chang et al., 2013; Stuckler et al., 2009). There have been increases in bereavement (with many being unusually complicated during the crisis), sales of alcohol (Finlay \& Gilmore, 2020) and domestic violence (Mahase, 2020) - all risk factors for suicide (Turecki et al., 2019); the insensitive or irresponsible media reporting of suicide deaths associated with COVID-19 may be harmful; and in some countries access to highly lethal suicide methods such as firearms and pesticides may rise (Gunnell et al., 2020).

In the context of the COVID-19 pandemic there is likely to be a rapidly expanding research evidence base on its impact on suicide rates, and how best to mitigate such effects. It is therefore important that the best available knowledge is made rapidly available to policymakers, public health specialists and clinicians. To facilitate this, we are conducting a living systematic review focusing on suicide prevention in relation to COVID-19. Living systematic reviews are high-quality, up-to-date online summaries of research that are regularly updated, using efficient, often semi-automated, systems of production (Elliott et al., 2014). This paper reports the first set of findings from the review, based on relevant articles identified up to June $7^{\text {th }} 2020$.

\section{Aim}

The overarching aim of the review is to identify and appraise any newly published evidence from around the world that assesses the impact of the COVID-19 pandemic on suicide deaths, suicidal behaviours, self-harm and suicidal thoughts, or that assesses the effectiveness of strategies to reduce the risk of suicide deaths, suicidal behaviours, self-harm and suicidal thoughts, resulting from the COVID-19 pandemic.

\section{Methods}

This living systematic review (Figure 1) follows published guidance for such reviews and for how expedited 'living' recommendations should be formed where relevant (Akl et al., 2017; Elliott et al., 2017). The review was prospectively registered (PROSPERO ID CRD42020183326; registered on 1 May 2020). An overview of our living review process is provided in Figure 1. A protocol (John et al., 2020a) was published in line with the Preferred Reporting Items for Systematic Review and Meta-Analysis Protocols guideline (Moher et al., 2015). Since publication of our protocol we have amended our methodology to: 1) search additionally the PsyArXiv and SocArXiv open access paper repositories; 2) include modelling studies within the scope of our review (e.g. to predict the likely impact of the pandemic on suicide rates); and 3) update our research questions to include adult self-neglect and parental neglect and fear of losing livelihood.

\section{Eligibility criteria}

Study participants may be adults or children of any ethnicities living in any country. Outcomes of interest are:

1. Deaths by suicide

2. Self-harm (intentional self-injury or self-poisoning regardless of motivation and intent) or attempted suicide (including hospital attendance and/or admission for these reasons)

3. Suicidal thoughts/ideation 


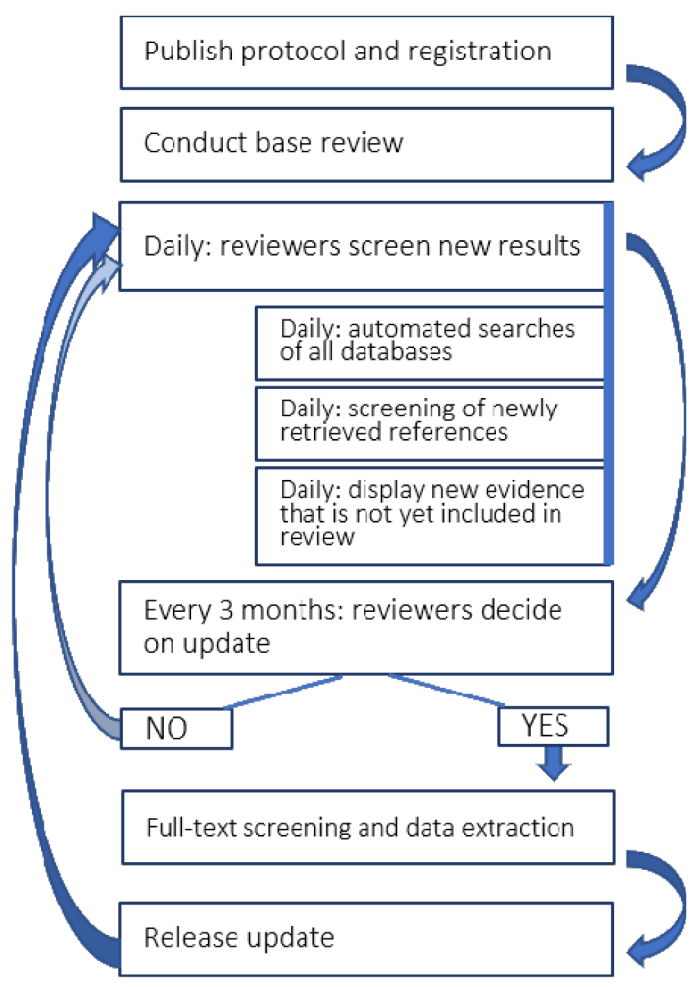

Figure 1. Workflow for updating the living systematic review review. The process will be supported using automation technology and at three-monthly intervals the team will update the published version of the review. The latest and previous versions of this figure are available as extended data (John \& Schmidt, 2020).

Studies must address one of the following research questions:

(i) What is the prevalence/incidence?

- Prevalence/incidence of each outcome during pandemic (including modelling studies)

(ii) What is the comparative prevalence/incidence?

- Prevalence/incidence of each outcome during pandemic vs not during pandemic

(iii) What are the effects of interventions?

- Effects of public health measures to combat COVID-19 (including physical distancing, school closures, interventions to address loss of income, interventions to tackle domestic violence) on each outcome

- Effects of changed and new approaches to clinical management of (perceived) elevated risk of self-harm or suicide risk on each outcome (any type of intervention is relevant)

(iv) What are the effects of other exposures?

- Impact of media portrayal of each outcome and misinformation attributed to the pandemic on each outcome

- Impact of bereavement from COVID-19 on each outcome
- Impact of any COVID-19 related behaviour changes (domestic violence, alcohol, adult self-neglect, parental neglect, cyberbullying, isolation) on each outcome

- Impact of COVID-19-related workload on crisis lines on each outcome

- Impact of infection with COVID-19 (self or family member) on each outcome

- Impact of changes in availability of analgesics, firearms and pesticides on each outcome (method-specific and overall suicide rates)

- Impact of COVID-19 related socio-economic exposures (changes in fiscal policy; recession/depression: unemployment, debt, fear of losing livelihood, deprivation at the person-, family- or small-area level) on each outcome

- Impact on health and social care professionals: the stigma of working with COVID-19 patients or the (perceived) risk of infection/being a 'carrier', as well as work-related stress on each outcome

- Impact of changes in/reduced intensity of treatment for patients with mental health conditions, in particular those with severe psychiatric disorders. 
- Impact of any other relevant exposure on our outcomes of interest.

\section{Qualitative research}

We include any qualitative research addressing perceptions or experiences around each outcome in relation to the COVID-19 pandemic (e.g. stigma of infection, isolation measures, complicated bereavement, media reporting, experience of delivering or receiving remote methods of self-harm/suicide risk assessment or provision of treatment; experience of seeking help for individuals in suicidal crisis); narratives provided for precipitating factors for each outcome.

No restrictions were placed on the types of study design eligible for inclusion, except for the exclusion of single-person case reports. Pre-prints were re-assessed at the time of publication and most current version included. There was no restriction on language of publication. We will draw on a combination of internet-based translation systems and network of colleagues to translate evidence in a language other than English.

\section{Identification of eligible studies}

We searched the following electronic databases: PubMed; Scopus; medRxiv, bioRxiv; the COVID-19 Open Research Dataset (CORD-19) by Semantic Scholar and the Allen Institute for AI, which includes relevant records from Microsoft Academic, Elsevier, arXiv and PMC; and the WHO COVID-19 database. A sample search strategy (for PubMed) appears in Box 1 from $1^{\text {st }}$ Jan 2020 to June $7^{\text {th }} 2020$. We have developed a workflow that automates daily searches of these databases, and the code supporting this process can be found at https://github. com/mcguinlu/COVID_suicide_living. Searches are conducted daily via PubMed and Scopus application programme interface and the bioRxiv and medRxiv RSS feeds. Conversion scripts for the daily updated WHO and the weekly updated CORD-19 corpus are used to collect information from the remaining sources. The software includes a systematic search function based on regular expressions to search results retrieved from the WHO, CORD-19 and preprint repositories (search strategy available in extended data (John \& Schmidt, 2020)). Our review is ongoing and we continue to investigate the use of other databases and to capture articles made available prior to peer review and assess eligibility and review internally. We therefore included PsyArXiv and SocArXiv repositories in our search strategy via their own open access platforms as we developed our automated system. For this version of the living review, Psy- and SocArXiv searches were carried out retrospectively on the $12^{\text {th }}$ of June, using a publication date filter for Jan $1^{\text {st }} 2020$ - June $7^{\text {th }} 2020$.

A two-stage screening process was undertaken to identify studies meeting the eligibility criteria. First, two authors (either $\mathrm{CO}$ or EE) assessed citations from the searches and identified potentially relevant titles and abstracts. Second, either DG, AJ or RW assessed the full texts of potentially eligible studies to identify studies to be included in the review. This process was managed via a custom-built online platform (Shiny web app, supported by a MongoDB database). The platform allowed for data extraction via a built-in form.

\section{Box 1. Search terms for PubMed}

((selfharm*[TIAB] OR self-harm*[TIAB] OR selfinjur*[TIAB] OR self-injur*[TIAB] OR selfmutilat*[TIAB] OR self-mutilat*[TIAB] OR suicid*[TIAB] OR parasuicid*[TIAB) OR (suicide[TIAB] OR suicidal ideation[TIAB] OR attempted suicide[TIAB]) OR (drug overdose[TIAB] OR self?poisoning[TIAB]) OR (self-injurious behavio?r[TIAB] OR self?mutilation[TIAB] OR automutilation[TIAB] OR suicidal behavio?r[TIAB] OR self?destructive behavio?r[TIAB] OR self?immolation[TIAB])) OR (cutt*[TIAB] OR head?bang[TIAB] OR overdose[TIAB] OR self?immolat*[TIAB] OR self?inflict*[TIAB]))) AND ((coronavirus disease?19[TIAB] OR sars?cov?2[TIAB] OR mers?cov[TIAB]) OR (19?ncov[TIAB] OR 2019?ncov[TIAB] OR n?cov[TIAB]) OR ("severe acute respiratory syndrome coronavirus 2" [Supplementary Concept] OR "COVID-19" [Supplementary Concept] OR COVID19 [tw] OR coronavirus [tw] OR nCoV[TIAB] OR HCoV[TIAB] OR ((virus*[Title] OR coronavirus[Title] OR nCoV[Title] OR infectious[Title] OR HCoV[Title] OR novel[Title])AND (Wuhan[Title] OR China[Title] OR Chinese[Title] OR 2019[Title] OR 19[Title] OR COVID*[Title] OR SARS-Cov-2[Title] OR NCP*[Title]) OR "Coronavirus"[MeSH]))))

\section{Data collection and assessment of risk of bias}

One author (DG, AJ or RW) extracted data from each included study using a piloted data extraction form (see extended data (John \& Schmidt, 2020)), and the extracted data were checked by one other author (AJ, or EE where AJ extracted data). Disagreements were resolved through discussion, and where this failed, by referral to a third reviewer (KH, NK or PM). Irrespective of study design, data source and outcome measure examined, the following basic data were extracted: citation; study aims and objectives; country/setting; characteristics of participants; methods; outcome measures (related to self-harm / suicidal behaviour and COVID-19); key findings; strengths and limitations; reviewer's notes. For articles where causal inferences are made - i.e. randomised or non-randomised studies examining the effects of interventions or aetiological epidemiological studies of the effects of exposures - we used a suitable version of the ROBINS-I or ROBINS-E tool to assess risk of bias as appropriate based on the research question and study design (Morgan et al., 2017; Sterne et al., 2016).

\section{Data synthesis}

We synthesised studies according to themes based on research questions and study design, using tables and narrative. Results were synthesised separately for studies in the general population, in health and social care staff and other at-risk occupations, and in vulnerable populations (e.g. people of older age or those with underlying conditions that predispose them to becoming severely ill or dying after contracting COVID-19). Where multiple studies addressed the same research questions, we assessed whether meta-analysis is appropriate and would conduct it where suitable, following standard guidance available in the Cochrane Handbook (Deeks et al., 2019). The current document is the first iteration of our review. We have not considered 
it appropriate to combine any results identified so far in a meta-analysis.

\section{Living review method}

Details of the living review method, justification for its use and our transition plan are provided in our protocol (John et al., 2020a). We plan to maintain the review in living mode for at least 12 months, from publication of the protocol $\left(25^{\text {th }}\right.$ June 2020). We will undertake monthly screening and consider full updates at least every three months. We will extend the living mode at 6-monthly intervals if evidence is still being published regularly. We anticipate an end to the living phase of the review at most 24 months after initiation, at which point we plan to publish the cumulated evidence in the form of a standard systematic review. Any decision to update the review more or less frequently will depend on the likely impact of the new evidence on the conclusions of the review. Impactful evidence may be (i) evidence that affects policy and/ or (ii) substantial, high-quality research studies (e.g. a randomised trial or population-based observational cohort study). Since we have not as yet identified any new evidence that impacts on the conclusions of this review we next update will include studies up to the $7^{\text {th }}$ of October 2020 after four months.

\section{Results}

In total, 2070 citations were identified by 7 June 2020 from all electronic searches, after duplicates were removed (Figure 2).
The cumulative numbers of articles over time that were identified by the search and included in the review are shown in Figure 3 and Figure 4.

\section{Description of included studies}

We included 29 articles in the review, describing 28 independent studies. In total, six studies spanned several countries or were worldwide, including those using online Amazon Mechanical Turk survey samples; six were from the United States; four from China; two from India; one each from Australia, Bangladesh, Canada, Germany, Greece, Pakistan, Spain, France and Switzerland. All articles were based on observational studies: eight were case series with a sample of two or more; 13 were cross sectional surveys (12 independent populations); five were modelling studies; and three were service utilisation studies. Studies are summarised by these study types in Table 1, Table 2, Table 3 and Table 4. Roughly half $(n=14)$ of the articles did not appear to have been peer reviewed. Ten articles were published as research letters to the Editor, four as pre-prints before peer review and in seven others there was a short time ( $<7$ days) between submission and acceptance.

\section{Study populations}

Two articles shared study populations (Killgore et al., 2020a; Killgore et al., 2020b). Excluding duplicate populations and modelling studies, the total number of unique participants was 33, 345. Most studies included both male and female

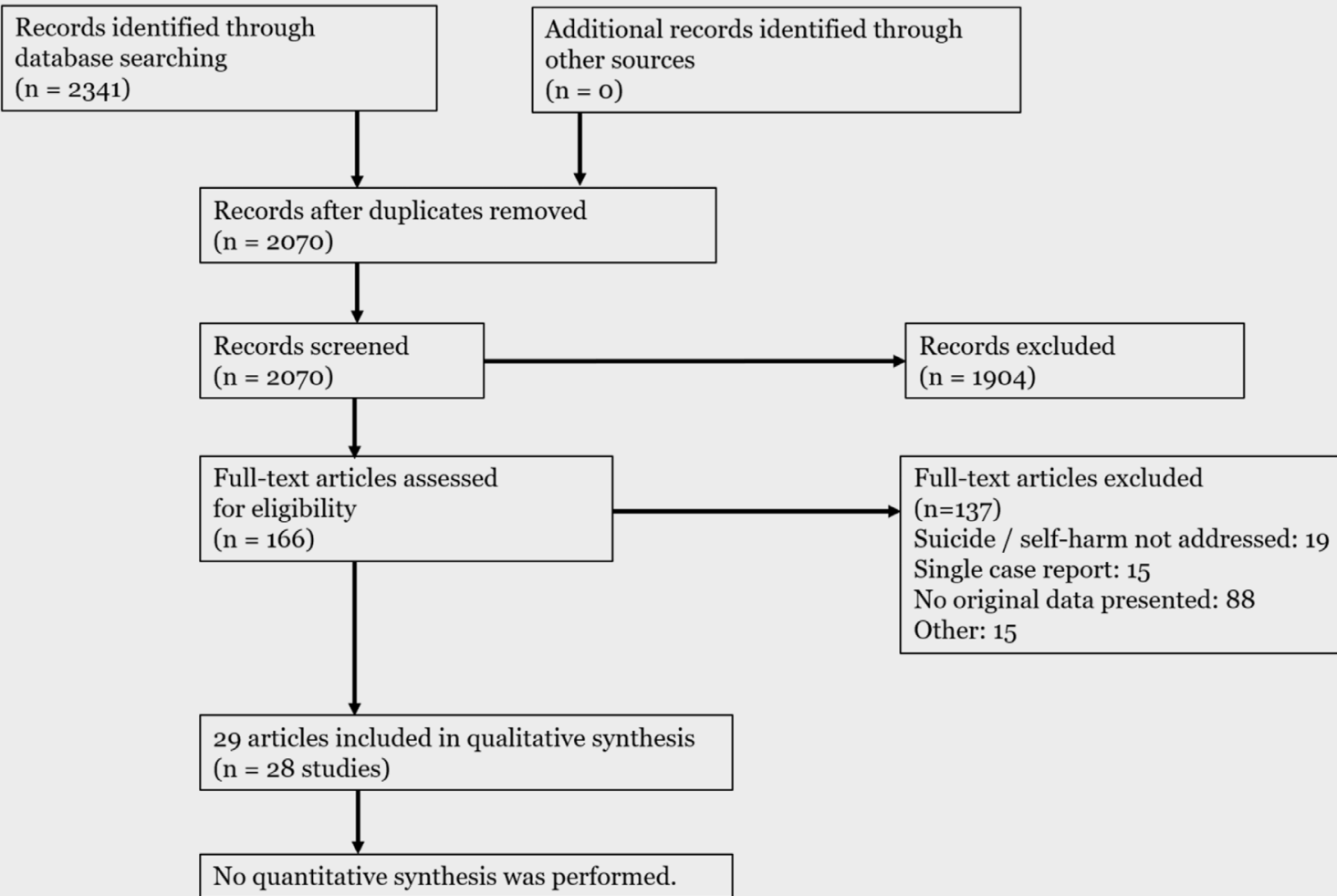

No quantitative synthesis was performed.

Figure 2. PRISMA flow diagram. The latest and previous versions of this figure are available as extended data (John \& Schmidt, 2020). 


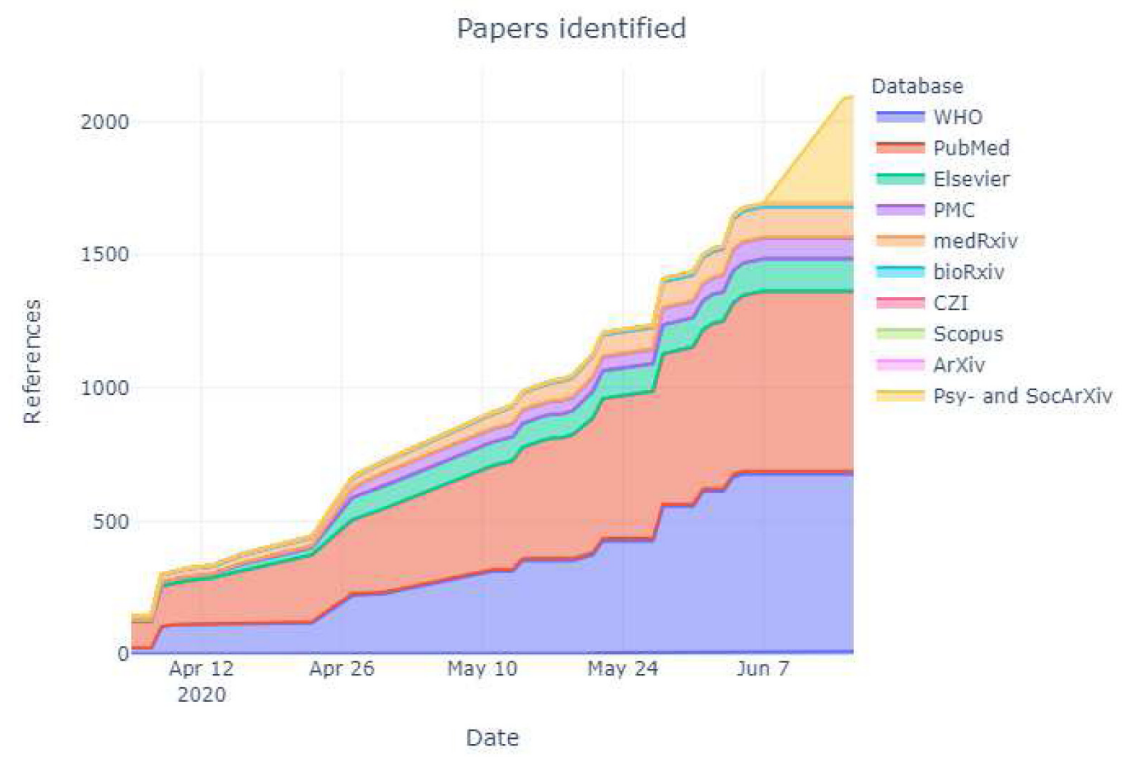

Figure 3. Number of articles identified by database and respository over time. The latest and previous versions of this figure are available as extended data (John \& Schmidt, 2020).

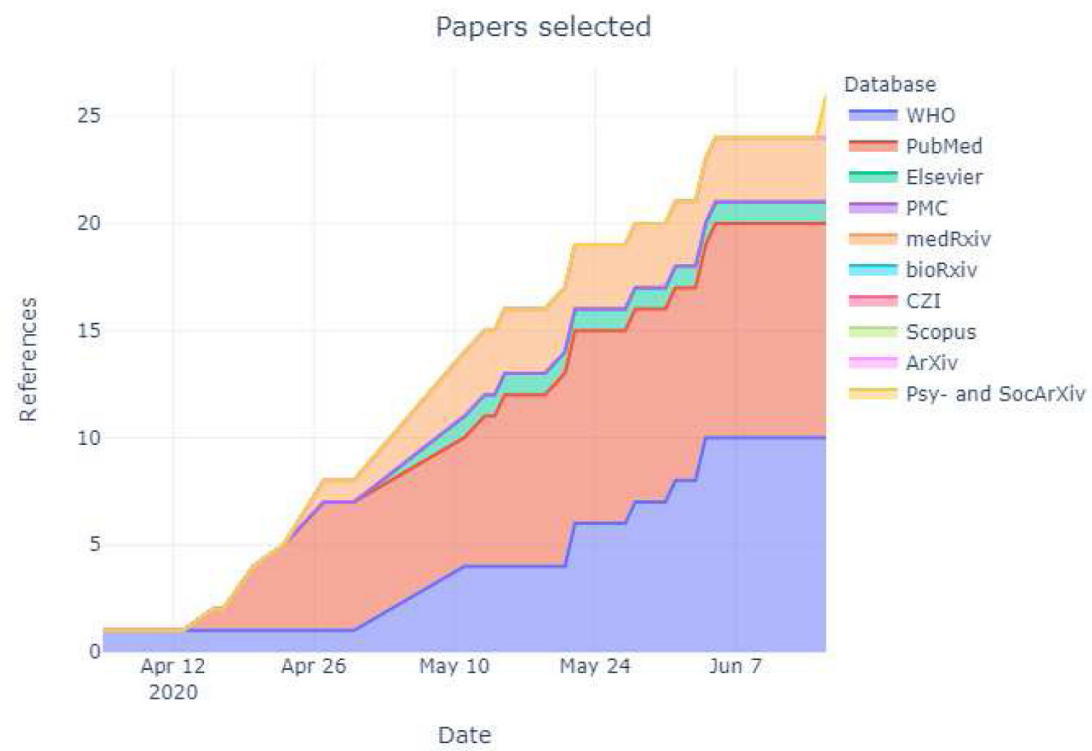

Figure 4. Number of articles selected by database and respository over time. The latest and previous versions of this figure are available as extended data (John \& Schmidt, 2020).

participants except (Wu et al., 2020b) which was conducted in a population of pregnant women in their third trimester.

\section{Outcomes}

Two of the eight case series focused on suicide attempts and six on suicide deaths. Of the 12 independent cross-sectional surveys ten assessed suicidal thoughts of which two also assessed suicide attempts (Ammerman et al., 2020; Bryan et al., 2020), one thoughts of self-harm (Wu et al., 2020b) using a single item from the Edinburgh Postnatal Depression Scale (EPDS), one suicidality (Kaparounaki et al., 2020) using the Risk Assessment Suicidality Scale (RASS). A range of validated questionnairres were used to assess suicidal thoughts. Four used the question 9 single item from PHQ-9 'Have you had thoughts that you would be better off dead or of hurting yourself in some way' with four levels of response ranging from 'not at all' to 'nearly every day' over the last 2 weeks. One each used: the Beck Depression Inventory-II (with one item where the participant choses 


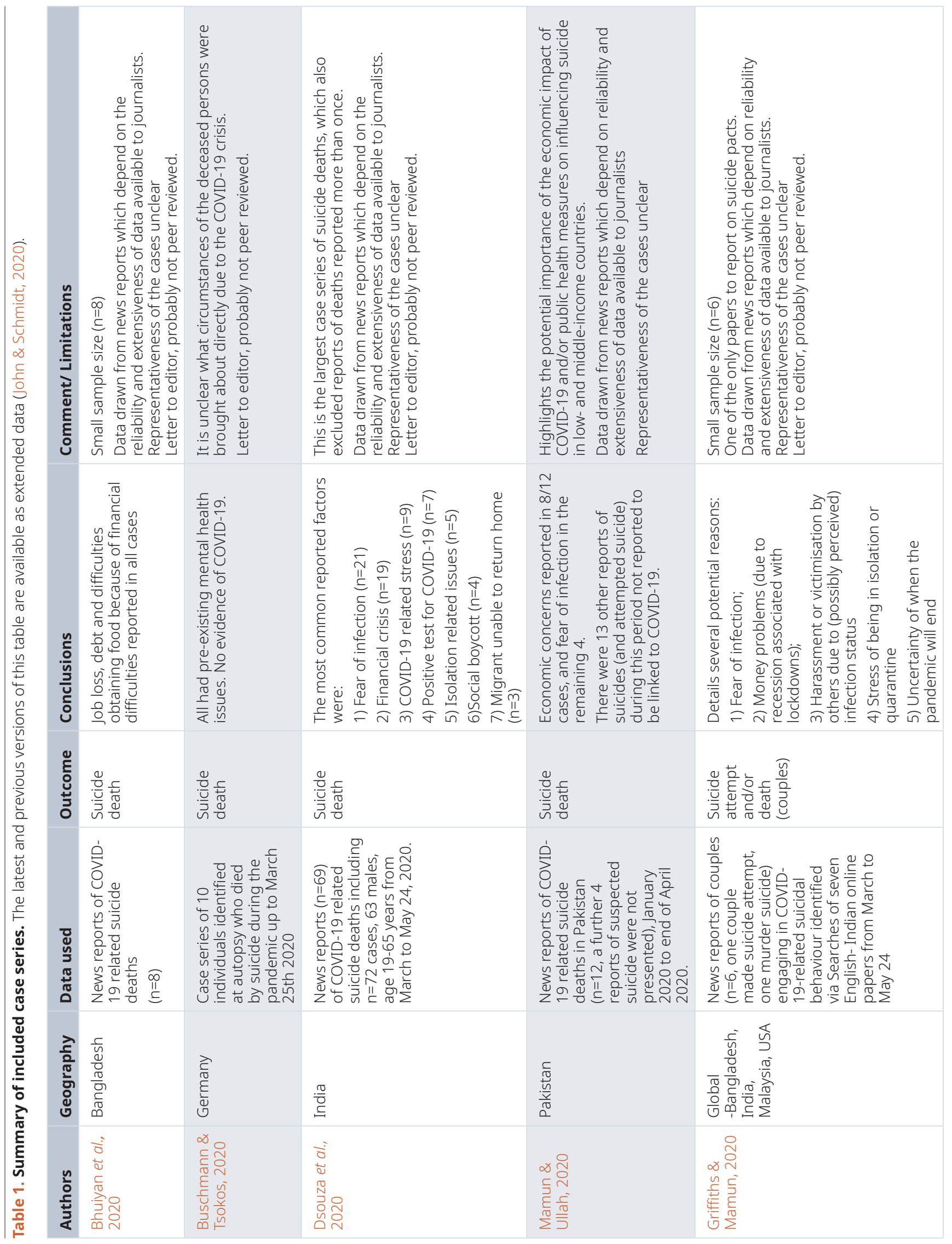




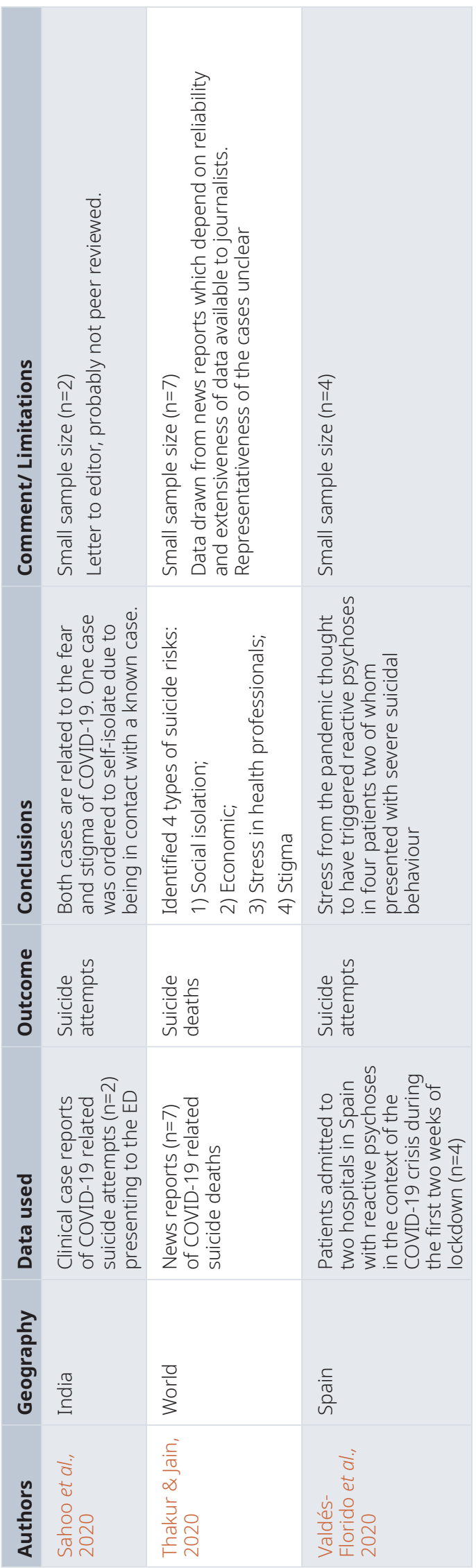




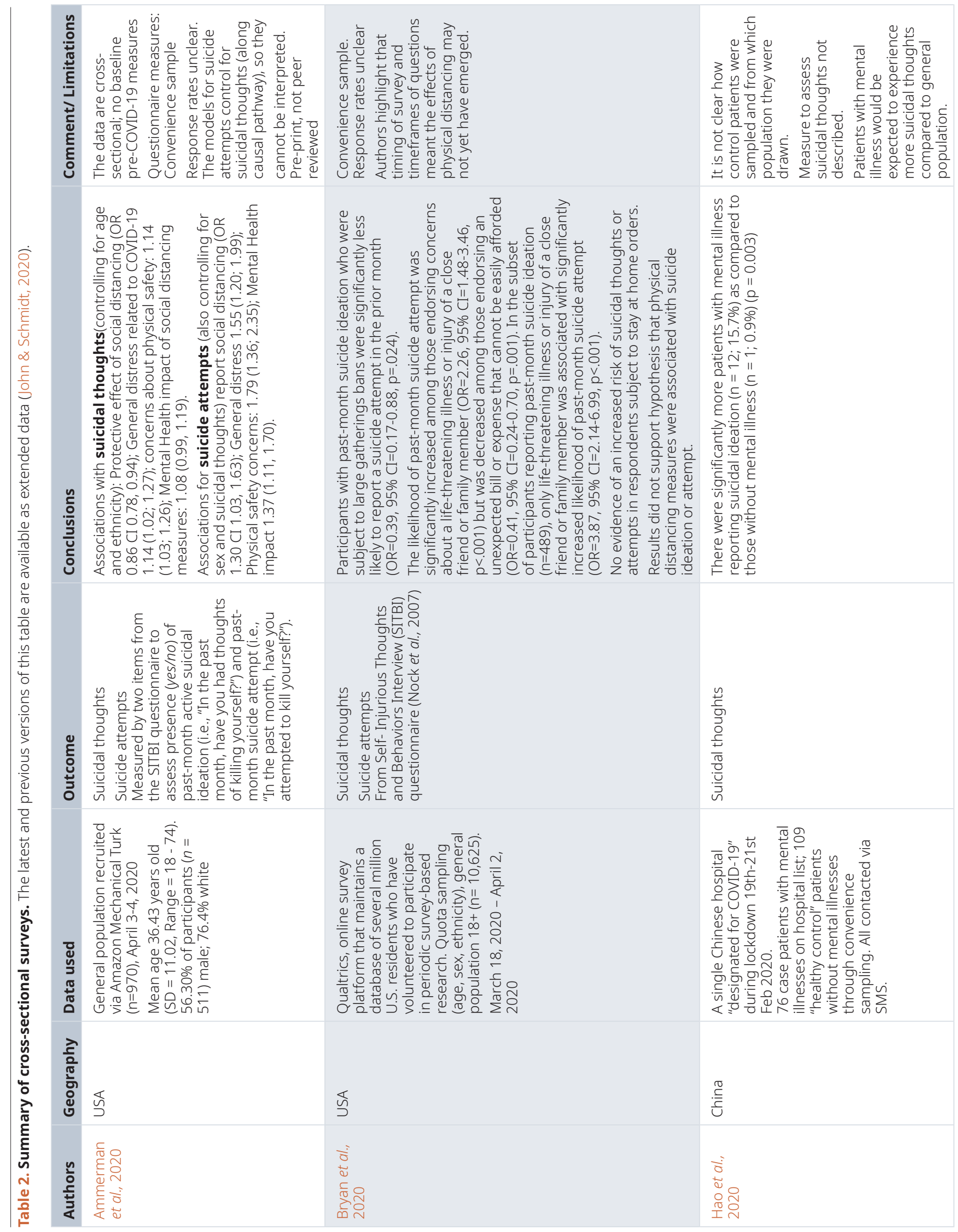



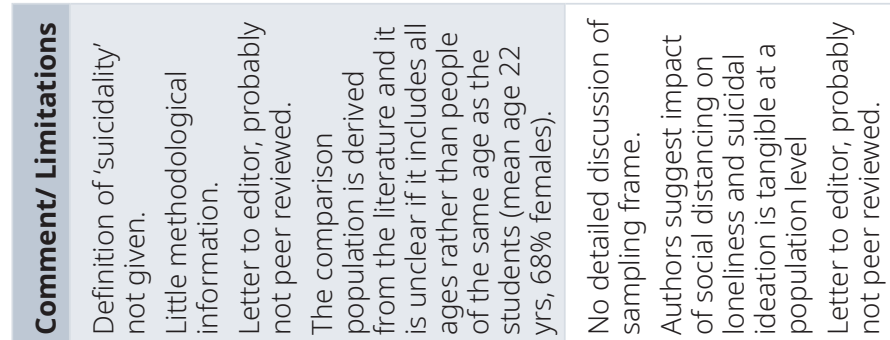

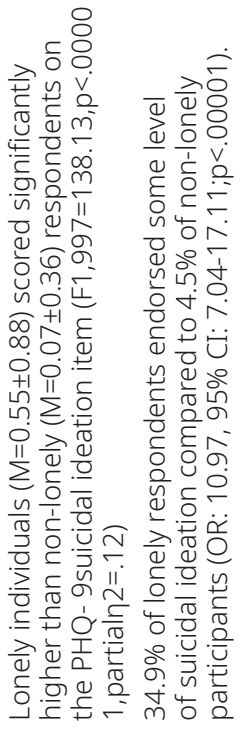

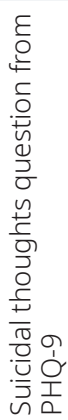

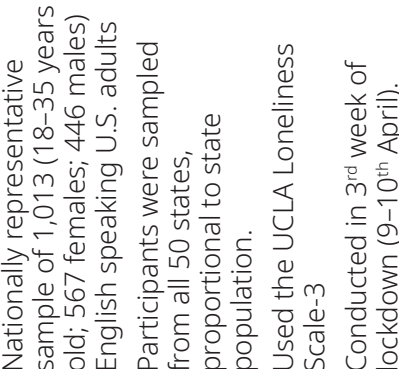

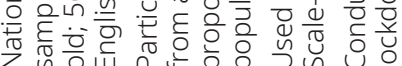

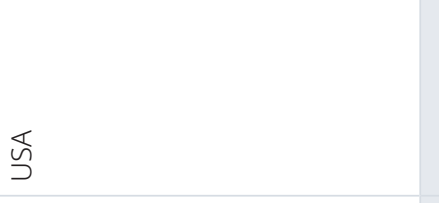

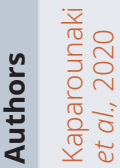
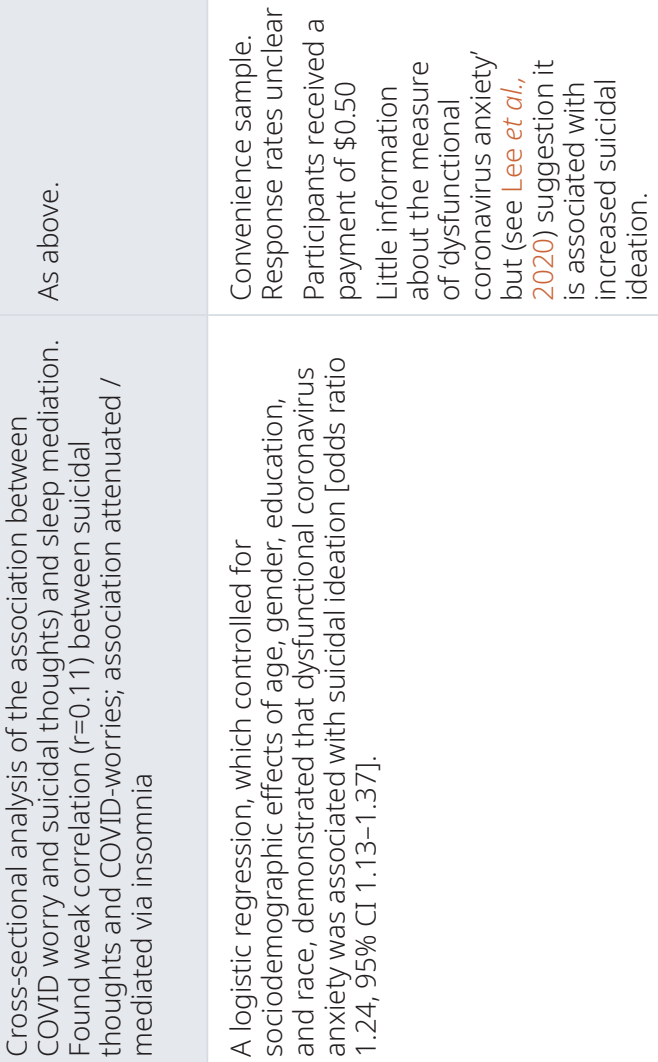

$=\frac{n}{\sum} \cdot \frac{0}{\frac{0}{0}}$

㐘 $\frac{0}{0} \frac{0}{0}$

궁 을

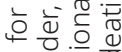

这

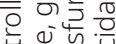

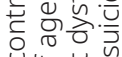

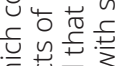

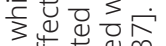

包过

을

U

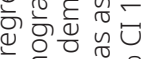

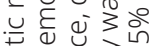

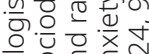

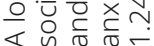

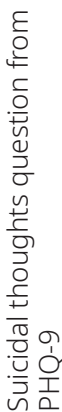
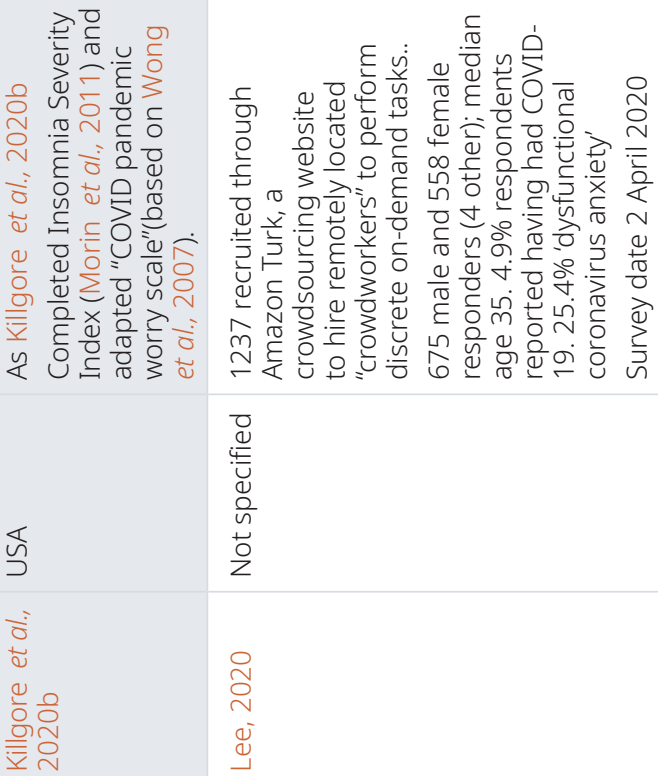


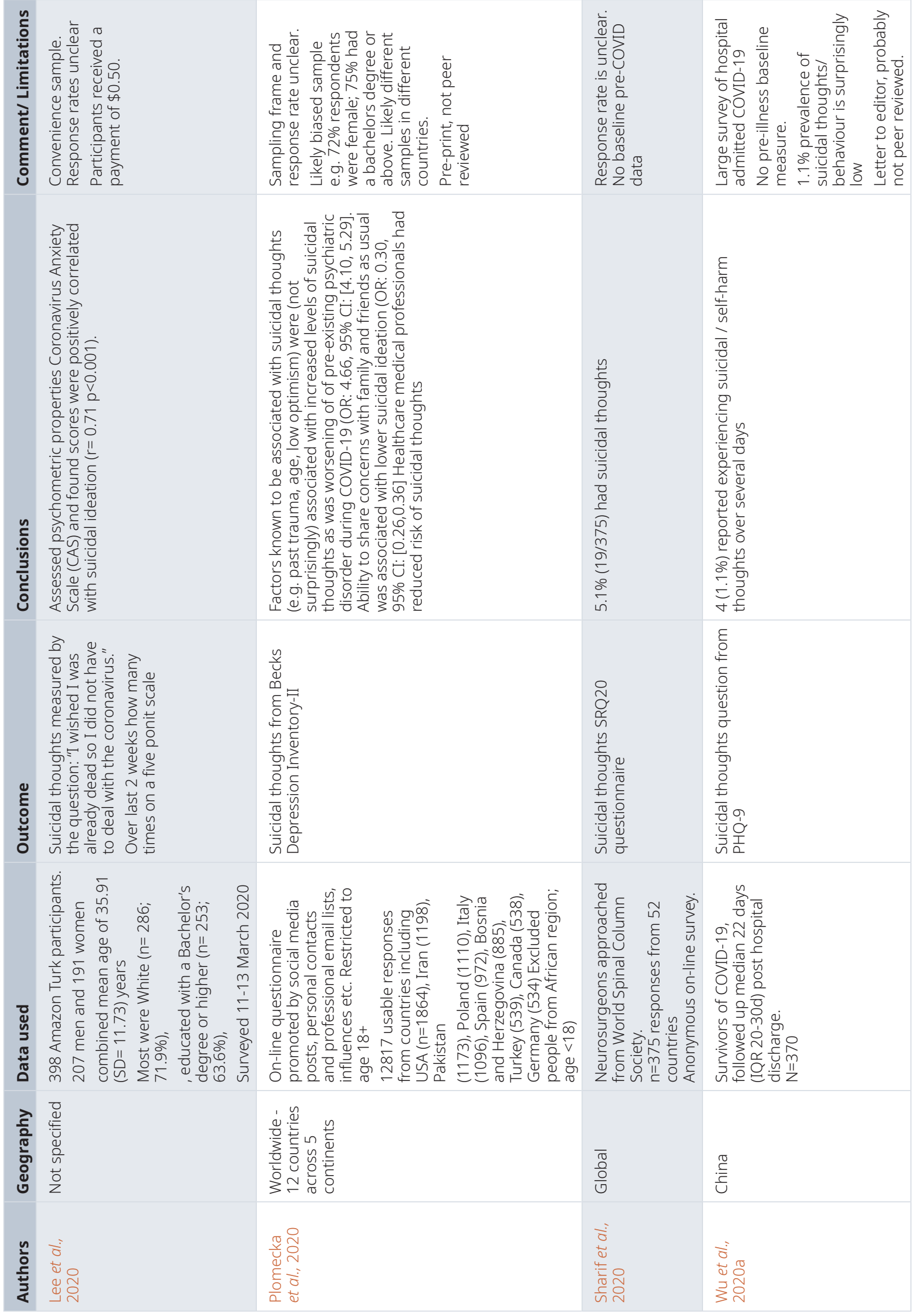




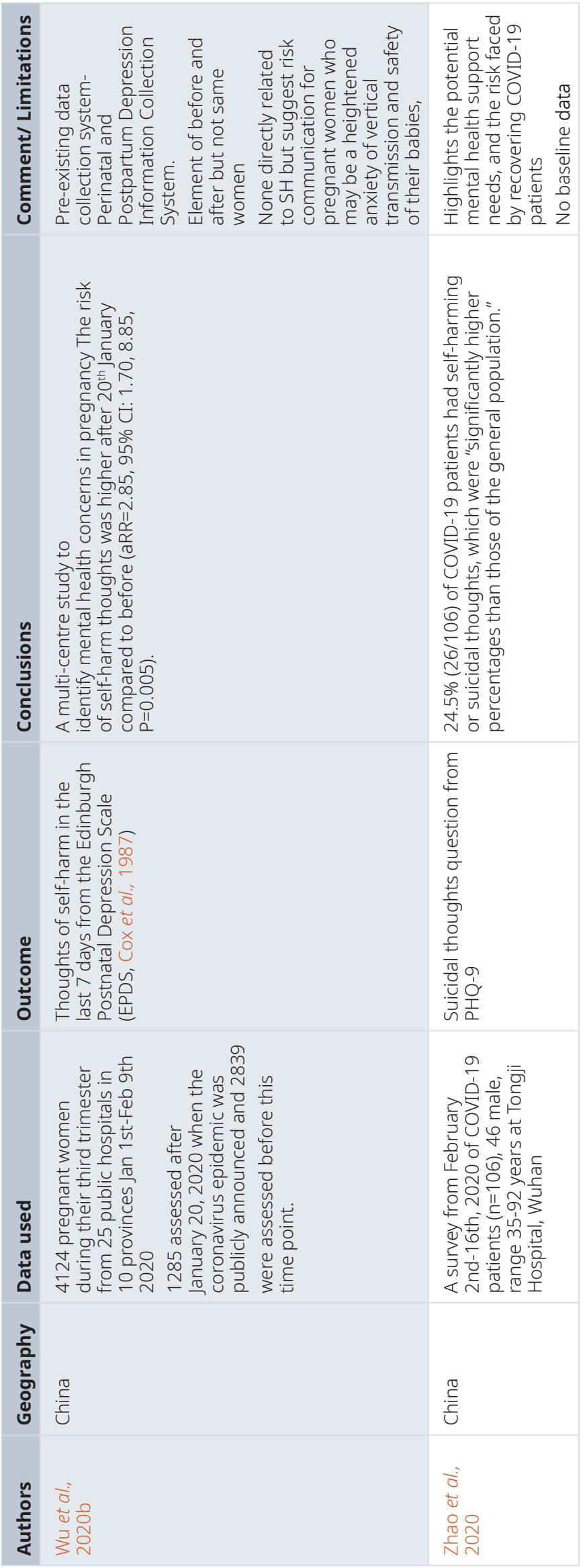




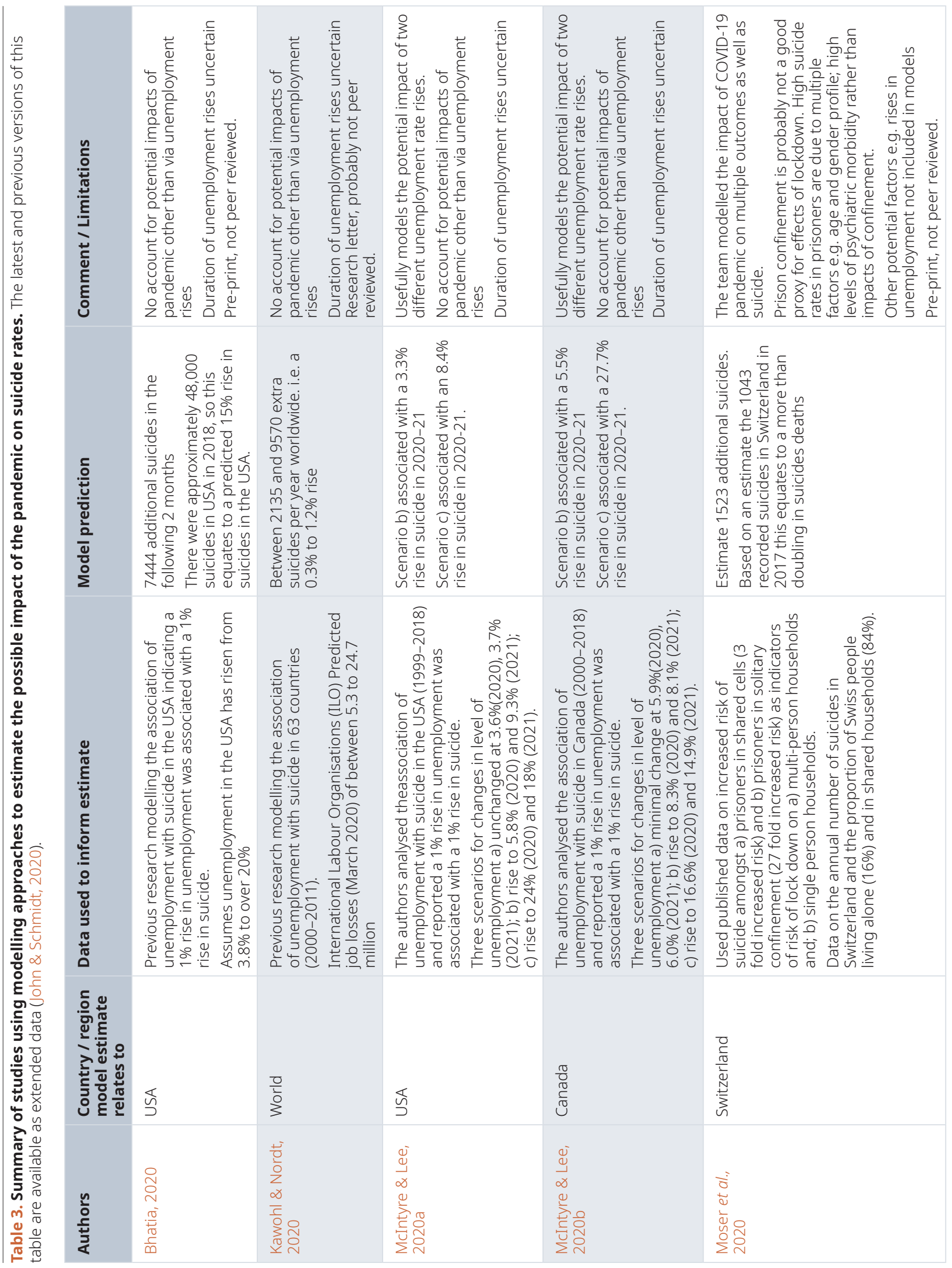




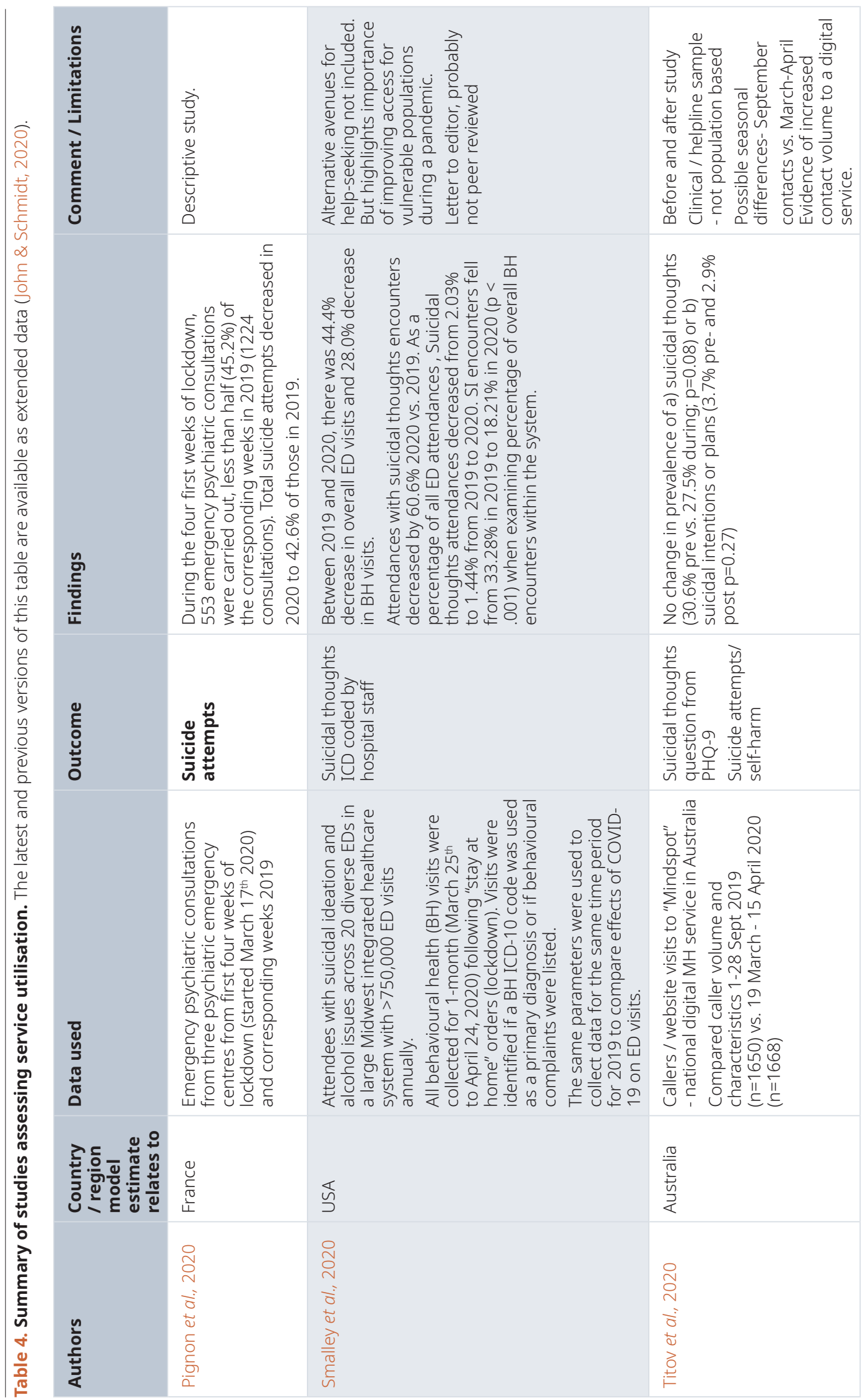


one statement from among a group of four statements that best describes how they have been feeling during the past few days, ranging from 'I don't have thoughts of killing myself' to 'I would kill myself if I had the chance'); the WHO Self Reporting Questionnaire (with one item of 20 asking 'Has the thought of ending your life been on your mind?', response yes/no in the last 30 days); one used the question how many times over the last two weeks have you thought 'I wished I was already dead so I did not have to deal with the coronavirus' on a five point scale; and in two little detail was given regarding this outcome assessment.

Two studies used the Self-injurous Thoughts and Behaviours Interview (SITBI) to assess for presence (yes/no) of active suicidal thoughts (i.e., 'Have you had thoughts of killing yourself?') in the past month (Ammerman et al., 2020) and the other in the past month, year or over a year ago (Bryan et al., 2020). They also included the item for suicide attempts. Ammerman et al. (2020) used one adapted item from the SITBI 'In the past month, have you attempted to kill yourself?' (yes/no) and Bryan et al. (2020) 'Have you ever made an actual attempt to kill yourself in which you had at least some intent to die?' (yes/no) within the past month, year or more than a year ago.

\section{Summary of studies' findings: Case series}

We identified eight case series reports of suicide attempts and suicide deaths (Table 1). Five of these used news reports as their data source (Bhuiyan et al., 2020; Dsouza et al., 2020; Griffiths \& Mamun, 2020; Mamun \& Ullah, 2020; Thakur \& Jain, 2020). Many reasons for COVID-19 related suicide or suicide attempts were suggested and usually this information was derived from a journalist's report of the death. Contributory factors reported included fear of contracting the disease or of passing it on to others, reactive psychoses, financial or economic issues, loneliness and isolation due to quarantine, stress among health professionals, the uncertainty around when the pandemic would end, an inability for migrants to return home, frustration and the stigma of a (possibly perceived) positive result, which resulted in harassment or victimisation by others in the community. The largest case series (Dsouza et al., 2020) ( $\mathrm{n}=72$ suicide deaths) reported that the most commonly occurring antecedents to suicide were fear of infection $(n=21)$ and financial crisis $(n=19)$. One case series (Griffiths \& Mamun, 2020), based on news reports, included suicide pacts by 6 couples (including one murder suicide and one double suicide attempt) from Bangladesh, India, Malaysia and the USA.

\section{Summary of studies' findings: Cross-sectional surveys}

There were 13 articles describing cross-sectional surveys, reporting 12 independent studies (Table 2). Seven articles (6 independent studies) reported cross-sectional surveys in the general population. One study (Killgore et al., 2020a; Killgore et al., 2020b) was a nationally representative sample of English speaking participants aged 18-35 years from 50 US states; however, no details were given regarding how the participants were sampled. Bryan et al. (2020) used a panel quota sampling methodology and weighted their sample to match the USA general population by age, sex and ethnicity. Three studies used convenience sampling through Amazon Mechanical Turk crowdsourcing (Ammerman et al., 2020; Lee, 2020; Lee et al., 2020), which pays survey responders a small fee for participation and one (Plomecka et al., 2020) used online recruitment.

Participants were COVID-19 patients in three studies (Hao et al., 2020; Wu et al., 2020a; Zhao et al., 2020) and surveys were targeted at specific poulations in a further three: pregnant women (Wu et al., 2020b)), neurosurgeons (Sharif et al., 2020) and university students (Kaparounaki et al., 2020). The study by Wu et al. (2020b) was the only survey to report pre-pandemic/ pre-illness data for comparison, although Killgore et al. (2020a) compared their findings to previous work (Morahan-Martin \& Schumacher, 2003) and a number of studies compared their findings to estimates that were reported from earlier published studies.

Higher levels of suicidal/self-harm thoughts were reported in individuals with: anxiety relating to COVID-19 (Lee, 2020); worry relating to COVID-19 mediated by insomnia (Killgore et al., 2020b); with loneliness (Killgore et al., 2020a); worsening of pre-existing mental illness during COVID-19 (Hao et al., 2020; Plomecka et al., 2020); and in students (Kaparounaki et al., 2020); people recovering from COVID-19 infection (Hao et al., 2020); as well as women who were in their third trimester of pregnancy during the pandemic, compared with measures taken amongst women at the same stage of pregnancy before the pandemic (Wu et al., 2020b). As these are cross-sectional studies the direction of association is not possible to determine and only one study used pre-pandemic measures recorded in the same population in a similar way (Wu et al., 2020b).

One study carried out in the USA exploited the natural experiment provided by states imposing physical distancing measures on different dates (Bryan et al., 2020). This study found no evidence of an increased risk of suicidal thoughts or attempts amongst those living in states with either stay-at-home orders or restrictions on large gatherings in place compared with states without these measures.

\section{Summary of studies' findings: Modelling studies}

We identified five studies (Table 3 ) that have used modelling approaches to forecast the potential impact of the pandemic on future suicide rates (Bhatia, 2020; Kawohl \& Nordt, 2020; McIntyre \& Lee, 2020a; McIntyre \& Lee, 2020b; Moser et al., 2020). Each was based on different assumptions, but models largely focused on the well-characterised impact on suicide rates of rises in unemployment (Chang et al., 2013; Stuckler et al., 2009). Unemployment rates are predicted to rise as a result of a post-pandemic recession, due to measures to control the spread of the virus on the wider economy and loss of work as many businesses have been forced to shut down.

Only one study modelled the effects of physical distancing measures on suicide rates (Moser et al., 2020); it did this by using suicide rates in prisoners in group or single cells as a model for lock-down in a group or in isolation. The prison population is exposed to multiple other risk factors for suicide 
(e.g. increased prevalence of mental illness, substance misuse and low socioeconomic position) (Humber et al., 2011; Rivlin et al., 2010), and this, coupled with the distinct differences between prison incarceration and the adoption of home quarantine procedures during the pandemic, this model is likely to over-estimate the potential impact of physical distancing measures on suicide.

The models suggest between a $1 \%$ rise (globally) (Kawohl \& Nordt, 2020) and a 145\% rise (in Switzerland) (Moser et al., 2020) in suicide deaths.

Summary of studies' findings: Service utilisation studies We identified three service utilisation studies (Pignon et al., 2020; Smalley et al., 2020; Titov et al., 2020) (Table 4). Smalley et al. (2020) reported a fall in ED visits for suicidal thoughts in Midwest USA, as well as a fall in the proportion of total visits that were for suicidal thoughts. In contrast Titov et al. (2020) found evidence of increased contact volume to a national digital mental health service in Australia. However, amongst contacts, while there was evidence of increased anxiety and levels of concerns about COVID-19, which increased with age, there was no evidence that the percentage of contacts with suicidal thoughts/plans increased. Pignon et al., 2020 reported that emergency psychiatric consultations for suicide attempts more than halved in a region of Paris in the first month of lockdown, compared to the same period in 2019.

\section{Discussion}

In total, 28 independent studies (29 articles) were included in this review covering a total of 33,345 studied individuals from around the world with a mix of low, middle and high income countries. Almost half of the articles were pre-prints published before peer review, or research letters that may not have been peer-reviewed. The majority of studies were case series or cross sectional surveys, almost all based on non-representative convenience samples. Only one study reported on the change in incidence of suicide or suicidal behaviour before versus after the onset of the pandemic (Pignon et al., 2020); this analysis was based on emergency psychiatric consultations for suicide attempt - and reported a decline, although levels of consultation could have been influenced by fears about using services or ideas of not burdening the health service rather than changes in incidence. A further study from China reported heightened levels of self-harm thoughts in pregnant women surveyed in the period after the onset of the pandemic, compared with levels reported amongst women surveyed at the same stage of pregnancy just before the pandemic (Wu et al., 2020b). No studies reported potentially harmful effects of lockdown/physical distancing measures in relation to our outcomes, although one study comparing the prevalence of suicidal thoughts and attempts in people living in USA states with varying timing and strigency of state-specific lockdowns found no evidence for such an ecological association (Bryan et al., 2020). Modelling studies that aimed to predict the impact of the pandemic on national or global suicide rates produced widely differing estimates of the likely impact and most focused on predictions based on previous studies of the impact of changes in unemployment levels on suicide. Three studies investgated service use patterns - one found a decline in ED visits for suicidal thoughts, one a decline in psychiatric emergency consultation for suicide attempt and the other reported an increase in contacts to a mental health digital platform but no changes in contacts for suicidal thoughts.

We identified eight case series reports of suicide attempts and suicide deaths, five based on news stories in India, Bangladesh and Pakistan. Given the relatively low quality of case series in the hierarchy of evidence, often reflecting small numbers and selection bias, but more importantly the lack of comparator data, drawing any reliable inferences from these studies is challenging. Furthermore, news reports report a non-representative sample of suicide deaths and often derive their information from bystanders and witnesses who are unlikely to know the full circumstances of the death (Khan et al., 2009). Nevertheless, these studies highlight circumstances surrounding apparently COVID-19-related suicides and flag the potential importance of factors such as economic difficulties, fear of the disease, and social isolation. Indeed in parts of the world without reliable suicide incidence data they may be the only source of information (Khan \& Hyder, 2006).

The 12 cross-sectional studies investigated a range of issues. Findings indicated worries about COVID-19 and recent COVID-19 infection were associated with suicidal thoughts (Hao et al., 2020; Killgore et al., 2020a; Killgore et al., 2020b; Lee, 2020; Lee et al., 2020; Zhao et al., 2020) and, amongst pregnant women surveyed during the pandemic, thoughts of self-harm were higher than amongst those surveyed pre-pandemic. The one study comparing suicidal thoughts and behaviours amongst people living in areas with versus without physical distancing measures found no adverse association (Bryan et al., 2020). Surprisingly survey by Ammerman et al. (2020) from the USA indicated that social distancing was associated with reduced instances of suicidal thoughts early in the period of lockdown. Only one survey suggested it was nationally representative but lacked sampling details (Killgore et al., 2020a). Non-probability sampling lacks a sound theoretical basis for statistical inference (Neyman, 1934). Consequently, basic descriptive analyses and explorations of potential associations are appropriate but measures of uncertainty (i.e., confidence intervals around estimates of prevalence) are generally not valid. One study (Bryan et al., 2020) used panel quota sampling, but these sorts of adjustments for age, sex and ethnicity may miss other elements of bias and cannot account for groups not included at all, particularly if the response rate is unknown (Pierce et al., 2020). Four studies used convenience sampling which tend to attract volunteers who have access to the internet, are already engaged in research and have an interest in the topic. Hence responses may be unrepresentative of the general population, and associations observed among these healthy volunteers may not reflect associations that would be observed in others. Similarly, when assessing suicidal thoughts and behaviours, those in most distress or with co-existing mental illness, as well as older people, are less likely to participate in these sorts of surveys. There is no way to assess non-response bias in a convenience sample as might be possible in a probability-sampled survey (Pierce et al., 2020). 
There was a large range in modelling estimates of the effect of the pandemic on suicide rates, varying between a $1 \%$ and a $145 \%$ rise. These differences between model estimates were partly due to differences in modelling assumptions, which are associated with considerable uncertainty. Given the methodological limitations, the uncertainty of assumptions about how the economies of individual countries will be affected, as well as international differences in financial supports given to businesses and people out of work, these predictive exercises can at best only provide a guide as to where action should be directed.

\section{Strengths and Limitations}

To date, there is little literature exploring COVID-19 and suicide deaths, suicidal behaviours, self-harm and suicidal thoughts and most of the published evidence that we identified had important limitations. Importantly, much of the literature is not yet peer reviewed so the quality of reported studies may change. There were eight research letters, five pre-prints and for many others very short timeframes between submission and acceptance. All included studies were observational in design and prone to multiple sources of bias (eg, recall bias, selection bias, confounding). No conclusions can be drawn regarding causality and temporality from cross sectional studies. However, such study designs may be appropriate in current circumstances where timeliness of studies to inform policy and practice are important. However many were carried out too quickly and too early (one to two weeks post lockdown) in the outbreak to make meaningful contributions to the evidence base. The lack of baseline data in the majority of surveys included in the review and adjustments made to standardised measures to assess suicidal behaviours as well as the range of measures and timing asked made assessment of findings problematic.

We did not include Google Trends studies (Jacobson et al., 2020; Knipe et al., 2020; Rana, 2020; Sinyor et al., 2020) since search data constitute a proxy measure but findings are largely mixed. We also excluded grey literature (Fancourt \& Steptoe, 2020).

\section{Implications}

A marked improvement in the quality of design, methods, and reporting in future studies is needed. There is thus far no clear evidence of an increase in suicidal behaviour or self-harm associated with the pandemic nor with the measures taken to curb the spread of COVID-19. The current iteration of out living review highlights the methodological issues of early evidence from around the world that assesses the impact of the COVID-19 pandemic on suicide deaths, suicidal behaviours, self-harm and suicidal thoughts, or that assesses the effectiveness of strategies to reduce the risk of suicide deaths, suicidal behaviours, self-harm and suicidal thoughts, resulting from the COVID-19 pandemic. However, suicide data are challenging to collect in real time and the economic effects are evolving. Our living review will provide a regular synthesis of the most up-to-date research evidence to guide public health and clinical policy to mitigate the impact of COVID-19 on suicide.

\section{Data availability}

\section{Underlying data}

Harvard Dataverse: Full review data for: "The impact of the COVID-19 pandemic on self-harm and suicidal behaviour: update of living systematic review". https://doi.org/10.7910/DVN/ 7WZXZK (John \& Schmidt, 2020)

This project contains the following underlying data:

- Screening_snapshot.csv (Screening progress for literature published before June 7th)

\section{Extended data}

Harvard Dataverse: Full review data for: "The impact of the COVID-19 pandemic on self-harm and suicidal behaviour: update of living systematic review". https://doi.org/10.7910/DVN/ 7WZXZK (John \& Schmidt, 2020)

This project contains the following extended data:

- LSR update tables and figures.docx (Tables and figures from this publication)

- PRISMA.doc

Data regarding the Protocol are available via our Harvard Dataverse repository for the protocol

Harvard Dataverse: Underlying data for: The impact of the Covid-19 pandemic on suicidal behaviour: a living systematic review protocol. https://doi.org/10.7910/DVN/9JYHLS (John et al., 2020b)

That project contains the following extended data:

- Search.docx (additional information about the searches, including full search strategies)

- Data extraction sheet/ study report

- Figure 1

- Prisma.pdf (the PRISMA-P statement)

- Prospero registration

Reporting guidelines

Harvard Dataverse: PRISMA checklist for 'The impact of the COVID-19 pandemic on self-harm and suicidal behaviour: a living systematic review' https://doi.org/10.7910/DVN/7WZXZK (John \& Schmidt, 2020)

Data are available under the terms of the Creative Commons Attribution 4.0 International license (CC-BY 4.0).

\section{Software availability}

The development version of the software for automated searching is available from Github: https://github.com/mcguinlu/COVID_ suicide_living.

Archived source code at time of publication: http://doi.org/ 10.5281/zenodo.3871366 (McGuinness \& Schmidt, 2020)

License: MIT 
Akl EA, Meerpohl JJ, Elliott J, et al.: Living systematic reviews: 4. Living guideline recommendations. J Clin Epidemiol. 2017; 91: 47-53. PubMed Abstract | Publisher Full Text

Ammerman BA, Burke TA, Jacobucci R, et al.: Preliminary Investigation of the Association Between COVID-19 and Suicidal Thoughts and Behaviors in the US. PsyArXiv. 2020

Publisher Full Text

Bhatia R: Predictions of Covid-19 Related Unemployment On Suicide and Excess Mortality in the United States. medRxiv. 2020.

Publisher Full Text

Bhuiyan AI, Sakib N, Pakpour AH, et al.: CoVID-19-related suicides in Bangladesh due to lockdown and economic factors: case study evidence

from media reports. Int J Ment Health Ad. 2020; 1-6.

PubMed Abstract | Publisher Full Text | Free Full Text

Bryan C, Bryan AO, Baker JC: Associations among state-level physical distancing measures and suicidal thoughts and behaviors among US adults during the early COVID-19 pandemic. PsyArXiv. 2020.

Publisher Full Text

Buschmann C, Tsokos M: Corona-associated suicide - Observations made in the autopsy room. Leg Med (Tokyo). 2020; 46: 101723.

PubMed Abstract | Publisher Full Text | Free Full Text

Chang SS, Stuckler D, Yip P, et al.: Impact of $\mathbf{2 0 0 8}$ global economic crisis on

suicide: time trend study in $\mathbf{5 4}$ countries. BMJ. 2013; 347: f5239.

PubMed Abstract | Publisher Full Text | Free Full Text

Cheung Y, Chau PH, Yip PS: A revisit on older adults suicides and Severe Acute Respiratory Syndrome (SARS) epidemic in Hong Kong. Int J Geriatr Psychiatry. 2008; 23(12): 1231-1238.

PubMed Abstract | Publisher Full Text

Cox J, Holden J, Sagovsky R: Detection of postnatal depression: Development of the 10-item Edinburgh Postnatal Depression Scale. Br J Psychiatry. 1987; 150:782-786.

PubMed Abstract | Publisher Full Text

Deeks IJ, Higgins JP, Altman DG, et al.: Chapter 10: Analysing data and undertaking meta-analyses. Cochrane handbook for systematic reviews of interventions. 2nd ed.: John Wiley \& Sons. 2019.

Reference Source

Dsouza DD, Quadros S, Hyderabadwala ZJ, et al.: Aggregated COVID-19 suicide incidences in India: Fear of COVID-19 infection is the prominent causative factor. Psychiatry Res. 2020; 290: 113145.

PubMed Abstract | Publisher Full Text

Elliott JH, Synnot A, Turner T, et al.: Living systematic review: 1.

Introduction-the why what, when, and how. J Clin Epidemiol. 2017: 91

23-30.

PubMed Abstract | Publisher Full Text

Elliott JH, Turner T, Clavisi O, et al.: Living systematic reviews: an emerging opportunity

e1001603.

PubMed Abstract | Publisher Full Text | Free Full Text

Fancourt D, Steptoe A: COVID-19 social study. Nuffield Foundation. 2020

Reference Source

Finlay I, Gilmore I: Covid-19 and alcohol-a dangerous cocktail. BMJ. 2020; 369: $\mathrm{m} 1987$

PubMed Abstract | Publisher Full Text

Griffiths MD, Mamun MA: COVID-19 suicidal behavior among couples and suicide pacts: Case study evidence from press reports. Psychiatry Res. 2020; 289: 113105.

PubMed Abstract | Publisher Full Text

Gunnell $D$, Appleby $L$, Arensman $E$, et al. Suicide risk and prevention during

the COVID-19 pandemic. Lancet Psychiatry. 2020; 7(6): 468-471.

PubMed Abstract | Publisher Full Text | Free Full Text

Hao F, Tan W, Jiang L, et al:: Do psychiatric patients experience more

psychiatric symptoms during COVID-19 pandemic and lockdown?

A case-control study with service and research implications for

immunopsychiatry. Brain Behav Immun. 2020; 87: 100-106.

PubMed Abstract | Publisher Full Text | Free Full Text

Holmes EA, O'Connor RC, Perry VH, et al:: Multidisciplinary research priorities

for the COVID-19 pandemic: a call for action for mental health science.

Lancet Psychiatry. 2020; 7(6): 547-560.

PubMed Abstract | Publisher Full Text | Free Full Text

Humber N, Piper M, Appleby L, et al.: Characteristics of and trends in

subgroups of prisoner suicides in England and Wales. Psychol Med. 2011;

41(11): 2275-2285.

PubMed Abstract | Publisher Full Text

Jacobson NC, Lekkas D, Price G, et al.: Flattening the Mental Health Curve:

COVID-19 Stay-at-Home Orders Are Associated With Alterations in Mental

Health Search Behavior in the United States. JMIR Ment Health. 2020; 7(6):

e19347.

PubMed Abstract | Publisher Full Text | Free Full Text

John A, Eyles E, Mcguinness LA, et al.: The impact of the COVID-19 pandemic on self-harm and suicidal behaviour: protocol for a living systematic review [version 1; peer review: 1 approved, 1 approved with reservations] F1000Research. 2020a; 9: 644 .

Publisher Full Text

John A, Eyles EC, McGuinness LA, et al.: Underlying data for: The impact of the Covid-19 pandemic on suicidal behaviour: a living systematic review protocol [Data set]. Harvard Dataverse. 2020b.

http://wwww.doi.org/10.7910/DVN/9JYHLS

John A, Schmidt L: "Full review data for: "The impact of the CovID-19 pandemic on self-harm and suicidal behaviour: update of living systematic review'"'. Harvard Dataverse, V3, 2020.

http://www.doi.org/10.7910/DVN/7WZXZK

Johnson NP, Mueller J: Updating the accounts: global mortality of the 1918-1920" Spanish" influenza pandemic. Bull Hist Med. 2002; 76(1): 105-115. PubMed Abstract | Publisher Full Text

Kaparounaki CK, Patsali ME, Mousa DPV, et al.: University students' mental health amidst the COVID-19 quarantine in Greece. Psychiatry Res. 2020; 290 113111.

PubMed Abstract | Publisher Full Text | Free Full Text

KawohI W, Nordt C: COVID-19, unemployment, and suicide. Lancet Psychiatry. 2020; 7(5): 389-390.

PubMed Abstract | Publisher Full Text | Free Full Text

Khan MM, Ahmed A, Khan SR: Female suicide rates in Ghizer, Pakistan.

Suicide Life Threat Behav. 2009; 39(2): 227-230.

PubMed Abstract | Publisher Full Text

Khan MM, Hyder AA: Suicides in the developing world: Case study from Pakistan. Suicide Life Threat Behav. 2006; 36(1): 76-81.

PubMed Abstract | Publisher Full Text

Killgore WD, Cloonan SA, Taylor EC, et al.: Loneliness: A signature mental health concern in the era of COVID-19. Psychiatry Res. 2020a; 290: 113117 PubMed Abstract | Publisher Full Text | Free Full Text

Killgore WD, Cloonan SA, Taylor EC, et al.: Suicidal ideation during the COVID-19 pandemic: the role of insomnia. Psychiatry Res. 2020b; 290: 113134. PubMed Abstract | Publisher Full Text | Free Full Text

Kisely S, Warren N, McMahon L, et al:: Occurrence, prevention, and management of the psychological effects of emerging virus outbreaks on healthcare workers: rapid review and meta-analysis. BMJ. 2020; 369. PubMed Abstract | Publisher Full Text | Free Full Text

Knipe $D$, Evans $H$, Marchant $A$, et al.: Mapping population mental health concerns related to COVID-19 and the consequences of physical distancing: a Google trends analysis [version 2; peer review: 2 approved] Wellcome Open Res. 2020; 5: 82

PubMed Abstract | Publisher Full Text | Free Full Text

Lee SA: Coronavirus Anxiety Scale: A brief mental health screener for COVID-19 related anxiety. Death Stud. 2020; 44(7): 393-401.

PubMed Abstract | Publisher Full Text

Lee SA, Mathis AA, Jobe MC, et al.: Clinically significant fear and anxiety of COVID-19: A psychometric examination of the Coronavirus Anxiety Scale. Psychiatry Res. 2020; 290: 113112

PubMed Abstract | Publisher Full Text | Free Full Text

Mahase E: Covid-19: EU states report $60 \%$ rise in emergency calls about domestic violence. $B M$ J. 2020; 369: $\mathrm{m} 1872$.

PubMed Abstract | Publisher Full Text

Mamun MA, Ullah I: COVID-19 suicides in Pakistan, dying off not COVID-19 fear but poverty?-The forthcoming economic challenges for a developing country. Brain Behav Immun. 2020; 87: 163-166.

PubMed Abstract | Publisher Full Text | Free Full Text

McGuinness LA, Schmidt L: mcguinlu/CovID suicide living: Initial Release

(v1.0.0) [Computer software]. Zenodo. 2020

http://www.doi.org/10.5281/ZENODO.3871366

Mcintyre RS, Lee Y: Preventing suicide in the context of the COVID-19

pandemic. World Psychiatry. 2020a: 19(2): 250-251.

PubMed Abstract | Publisher Full Text | Free Full Text

Mcintyre RS, Lee Y: Projected increases in suicide in Canada as a

consequence of COVID-19. Psychiatry Res. 2020b; 290: 113104

PubMed Abstract | Publisher Full Text | Free Full Text

Moher D, Shamseer L, Clarke M, et al.: Preferred reporting items for systematic review and meta-analysis protocols (PRISMA-P) 2015 statement. Syst Rev. 2015; 4(1): 1.

PubMed Abstract | Publisher Full Text | Free Full Text

Morahan-martin J, Schumacher P: Loneliness and social uses of the Internet. Comput Hum Behav. 2003; 19(6): 659-671.

Publisher Full Text

Morgan R, Sterne JA, Higgins JP, et al:: A new instrument to assess Risk of Bias in Non-randomised Studies of Exposures (ROBINS-E): Application to studies of environmental exposure Global Evidence Summit. Cape Town. 2017. 
Morin CM, Belleville G, Bélanger L, et al.: The Insomnia Severity Index: psychometric indicators to detect insomnia cases and evaluate treatment response. Sleep. 2011; 34(5): 601-608.

PubMed Abstract | Publisher Full Text | Free Full Text

Moser DA, Glaus J, Frangou S, et al.: Years of life lost due to the psychosocia consequences of COVID19 mitigation strategies based on Swiss data. Eur Psychiatry. 2020; 63(1): e58.

PubMed Abstract | Publisher Full Text | Free Full Text

Neyman J: On the two different aspects of the representative method: the method of stratified sampling and the method of purposive selection. $J R$

Stat Soc B. 1934; 97(4): 558-625.

Publisher Full Text

Pierce M, Mcmanus S, Jessop C, et al.: Says who? The significance of sampling in mental health surveys during COVID-19. Lancet Psychiatry. 2020; 7(7): 567-568.

PubMed Abstract | Publisher Full Text | Free Full Text

Pignon B, Gourevitch R, Tebeka S, et al.: Dramatic reduction of psychiatric emergency consultations during lockdown linked to COVID-19 in Paris and suburbs. Psychiatry Clin Neurosci. 2020.

PubMed Abstract | Publisher Full Text | Free Full Tex

Plomecka MB, Gobbi S, Neckels R, et al.: Mental Health Impact of COVID-19: A global study of risk and resilience factors. medRxiv. 2020.

Publisher Full Text

Rana U: Elderly Suicides in India: An Emerging Concern during COVID-19 Pandemic. Int Psychogeriatr. 2020; 1-2.

PubMed Abstract | Publisher Full Text | Free Full Text

Reger MA, Stanley IH, Joiner TE: Suicide Mortality and Coronavirus Disease 2019-A Perfect Storm? JAMA Psychiatry. 2020

PubMed Abstract | Publisher Full Text

Rivlin A, Hawton K, Marzano L, et al.: Psychiatric disorders in male prisoners who made near-lethal suicide attempts: case-control study. Br J Psychiatry. 2010; 197(4): 313-319.

PubMed Abstract | Publisher Full Text

Sahoo S, Bharadwaj S, Parveen S, et al.: Self-harm and CovID-19 Pandemic: An emerging concern-A report of 2 cases from India. Asian J Psychiatr. 2020; 51: 102104

PubMed Abstract | Publisher Full Text | Free Full Text

Sharif S, Amin F, Hafiz M, et al.: COVID 19-Depression and Neurosurgeons. World Neurosurg. 2020; 140: e401-e410.

PubMed Abstract | Publisher Full Text | Free Full Text

Sinyor M, Spittal MJ, Niederkrotenthaler T: Changes in Suicide and Resiliencerelated Google Searches during the Early Stages of the COVID-19

Pandemic. Can J Psychiatry. 2020; 706743720933426.

PubMed Abstract | Publisher Full Text
Smalley CM, Malone DA, Meldon SW, et al.: The impact of COVID-19 on suicidal ideation and alcohol presentations to emergency departments in a large healthcare system. Am J Emerg Med. 2020; S0735-6757(20)30457-5. PubMed Abstract | Publisher Full Text | Free Full Text

Sterne JA, HernÁn MA, Reeves BC, et al.: ROBINS-I: a tool for assessing risk of bias in non-randomised studies of interventions. BMJ. 2016; 355: i4919. PubMed Abstract | Publisher Full Text | Free Full Text

Stuckler D, Basu S, Suhrcke M, et al.: The public health effect of economic crises and alternative policy responses in Europe: an empirical analysis. Lancet. 2009; 374(9686): 315-323.

PubMed Abstract | Publisher Full

Thakur V, Jain A: COVID 2019-suicides: A global psychological pandemic. Brain Behav Immun. 2020; 88: 952-953.

PubMed Abstract | Publisher Full Text | Free Full Text

Titov N, Staples L, Kayrouz R, et al.: Rapid report: Early demand, profiles and concerns of mental health users during the coronavirus (COVID-19) pandemic. Internet Interv. 2020; 21: 100327.

PubMed Abstract | Publisher Full Text | Free Full Text

Turecki G, Brent DA, Gunnell D, et al.: Suicide and suicide risk. Nat Rev Dis

Primers. 2019; 5: 73

Publisher Full Text

Valdés-Florido MJ, López-Díaz A, Palermo-Zeballos FJ, et al.: Reactive psychoses in the context of the COVID-19 pandemic: clinical perspectives from a case series. Rev Psiquiatr Salud Ment. 2020; 13(2): 90-94.

PubMed Abstract | Publisher Full Text | Free Full Text

Wasserman IM: The impact of epidemic,war prohibition and media on suicide: United States, 1910-1920. Suicide Life Threat Behav. 1992; 22(2): 240-254. PubMed Abstract

Wong TW, Gao Y, Tam WWS: Anxiety among university students during the SARS epidemic in Hong Kong. Stress Health. 2007; 23(1): 31-35.

Publisher Full Text | Free Full Text

Worldometer: Covid-19 Coronavirus Pandemic [Online]. 2020. [Accessed 07/06/2020]

Reference Source

Wu C, Hu X, Song J, et al:: Mental health status and related influencing factors of COVID-19 survivors in Wuhan, China. Clin Transl Med. 2020a; 10(2): e52.

PubMed Abstract | Publisher Full Text | Free Full Text

Wu Y, Zhang $\mathrm{C}$, Liu $\mathrm{H}$, et al.: Perinatal depressive and anxiety symptoms of pregnant women along with COVID-19 outbreak in China. Am J Obstet Gynecol. 2020b; 223(2): 240.e1-240.e9.

PubMed Abstract | Publisher Full Text | Free Full Text

Zhao Q, Hu C, Feng R, et al.: Investigation of the mental health of patients with novel coronavirus pneumonia. Chinese Journal of Neurology. 2020. 


\section{Open Peer Review}

\section{Current Peer Review Status: $\checkmark$ ? ?}

\section{Version 1}

Reviewer Report 08 February 2021

https://doi.org/10.5256/f1000research.28166.r77902

(C) 2021 Martinez-Ales G. This is an open access peer review report distributed under the terms of the Creative Commons Attribution License, which permits unrestricted use, distribution, and reproduction in any medium, provided the original work is properly cited.

\section{Gonzalo Martinez-Ales}

Mailman School of Public Health, Columbia University, New York, NY, USA

This manuscript is a great scientific contribution. The main strength of the manuscript (that it builds on a remarkable effort -- their living systematic review) goes hand in hand with the most important limitation (the period included in the particular iteration that is under consideration for publication). I would like to thank the authors for such a great addition to science (the living systematic review) and express my admiration. Next, I expand on these observations.

The introduction is right on target and reads well. A reference to recent increases in gun purchases in the US (e.g., https://www.businessinsider.com/gun-sales-boom-2020-backgroundchecks-hit-record-highs-2021-1). Methods are sound. Results are concise and informative. The tables are particularly interesting and we congratulate the authors on the table including modelling studies as it conveys the most important information easily. The discussion also reads well and adjusts well to the findings.

There is, however, a major limitation to this study that authors may want to address: the limited period of time included. This iteration of the review stopped including papers by July 7th, roughly 4 months after the pandemic hit Western countries for the first time. Notably, this review would have been of great interest if published over the summer. Several research reports (and important grey literature) have become public in the meantime, some adding to the evidence reviewed here without notably changing the overarching results but enhancing their reliability (and probably creating the necessary ground for a quantitative summary or a meta-analysis) and, more importantly, some creating groundbreaking evidence that may change the conclusion of this review (such as the Nature Comms paper by Tanaka and Okamoto using data from Japan to show an initial dip and subsequent increase in suicide rates in Japan).

See some key recent key additions to the literature as an example:

https://www.nature.com/articles/s41562-020-01042-z'

https://www.medrxiv.org/content/10.1101/2020.11.13.20231571v12 
https://www.medrxiv.org/content/10.1101/2020.10.06.20207530v533

https://www.medrxiv.org/content/10.1101/2020.10.21.20187419v14

https://www.medrxiv.org/content/10.1101/2020.10.20.20215343v1 ${ }^{5}$

The impact of this profound and sound review is somewhat limited by the period included: readers should resort to the authors' ongoing live review.

\section{References}

1. Tanaka T, Okamoto S: Increase in suicide following an initial decline during the COVID-19 pandemic in Japan.Nat Hum Behav. 2021. PubMed Abstract | Publisher Full Text

2. Vandoros S, Theodorikakou O, Katsadoros K, Zafeiropoulou D, et al.: No evidence of increase in suicide in Greece during the first wave of Covid-19. medRxiv. 2020. Publisher Full Text

3. Ueda M, Nordström R, Matsubayashi T: Suicide and mental health during the COVID-19 pandemic in Japan. medRxiv. 2020. Publisher Full Text

4. Radeloff D, Papsdorf R, Uhlig K, Vasilache A, et al.: Trends in suicide rates during the COVID-19 pandemic restrictions in a major German city. medRxiv. 2020. Publisher Full Text

5. Faust J, Shah S, Du C, Li S, et al.: Suicide Deaths during the Stay-at-Home Advisory in Massachusetts. medRxiv. 2020. Publisher Full Text

Are the rationale for, and objectives of, the Systematic Review clearly stated?

Yes

Are sufficient details of the methods and analysis provided to allow replication by others? Yes

Is the statistical analysis and its interpretation appropriate?

Not applicable

Are the conclusions drawn adequately supported by the results presented in the review? Yes

Competing Interests: Only competing interest is that I served as co-author in a published paper that is included in the living review but not in this iteration.

Reviewer Expertise: Psychiatric epidemiology.

I confirm that I have read this submission and believe that I have an appropriate level of expertise to confirm that it is of an acceptable scientific standard, however I have significant reservations, as outlined above.

Reviewer Report 11 January 2021

https://doi.org/10.5256/f1000research.28166.r75857 
(c) 2021 Van Orden $\mathbf{K}$. This is an open access peer review report distributed under the terms of the Creative Commons Attribution License, which permits unrestricted use, distribution, and reproduction in any medium, provided the original work is properly cited.

\section{Kimberly A Van Orden}

Department of Psychiatry, University of Rochester Medical Center, Rochester, New York, USA

This article provides a review of empirical studies on suicide ideation, behavior, and deaths as related to the COVID-19 pandemic (up to June 2020). Given prior data linking disasters and crises more generally, and pandemics specifically, to changes in suicide rates, describing any changes in suicide rates (as well as suicide ideation and non-fatal behavior) due to the COVID-19 pandemic could contribute to suicide prevention science and promote public health efforts to save lives. A key strength of this paper is its design as a 'living review' that will be updated every six months as more data is available. Another strength is the transparent reporting on search methods and strategies.

A limitation of the paper is inadequate attention to study quality in the analysis and interpretation of findings. I will give several examples. First, the authors report that they used a formal tool to assess the risk of bias for epidemiological or clinical trial design studies, but do not report findings from these assessments; given that many papers included in the review were not peer reviewed, it seems especially useful for the authors to use such assessments of study quality to guide their review and to 'weight' findings from these studies in their analysis. Second, the degree of methodological rigor could be assessed for all studies, not just those with epidemiology/clinical trial designs and the authors should consider doing so. Third, the authors indicate in the primary table that letters to the editor were 'probably not peer reviewed.' Given that this information could be verified by contacting the journals, this would be a useful strategy to bolster findings from this review. Fourth, when the authors describe the findings, they do not differentiate between findings that appear methodologically-sound versus those that may not be, thus negating one of the most useful features of review papers for readers.

Another limitation of the paper is that it provides relatively little synthesis or conclusions, which is a key function of review papers, as opposed to a database that contains a listing of available studies. The discussion section includes more of a summary of what studies examined (and did not examine) as opposed to a synthesis of findings. The authors do not provide a nuanced discussion of the fact that these studies come from numerous countries around the world and what addressing this issue could potentially tell us about possible variability in suicide rates around the world. They do not discuss limitations with sampling that appeared across studies (e.g., generalizability of online platforms like M-Turk). In the discussion section, the authors conclude that "a marked improvement in the quality of design, methods, and reporting in future studies is needed." This may be accurate, but I do not think it is an especially useful statement to guide the field. A more useful set of statements might involve a synthesis of methodological strengths and weaknesses as well as a discussion on strategies that can be taken going forward to address these weaknesses. The authors do not posit further implications; this may be accurate-that nothing else can be concluded right now-but in that case, perhaps the paper is premature.

The authors should provide additional details on the methods used for the review process to 
construct Tables 1-4. In particular, for the column labeled 'Conclusions,' presumably, this refers to conclusions made by the authors of the original papers? This should be stated explicitly. Did the authors of this review include all conclusions made by the authors of the original studies in the table or did they select ones deemed most useful? How did the authors of this review select the limitations and comments included in the final column? Some of the comments included in that final column appear opinion-based and are not supported by data from the papers (e.g., prevalence is "surprisingly low" or these data "cannot be interpreted" and "usefully").

For future updates, the authors should consider providing dates for data collection in their tables given that the timing of when studies are conducted may moderate findings, given the variability in length of physical distancing, amount of economic disruption, and the number of deaths due to COVID-19.

Are the rationale for, and objectives of, the Systematic Review clearly stated? Yes

Are sufficient details of the methods and analysis provided to allow replication by others? No

Is the statistical analysis and its interpretation appropriate?

Not applicable

Are the conclusions drawn adequately supported by the results presented in the review? Partly

Competing Interests: No competing interests were disclosed.

Reviewer Expertise: Suicide prevention

I confirm that I have read this submission and believe that I have an appropriate level of expertise to confirm that it is of an acceptable scientific standard, however I have significant reservations, as outlined above.

Reviewer Report 22 September 2020

https://doi.org/10.5256/f1000research.28166.r71350

(c) 2020 Vijayakumar L. This is an open access peer review report distributed under the terms of the Creative Commons Attribution License, which permits unrestricted use, distribution, and reproduction in any medium, provided the original work is properly cited.

\section{Lakshmi Vijayakumar}

Department of Psychiatry, VHS SNEHA (Suicide Prevention Agency), Chennai, Tamil Nadu, India

This is a much needed study during the pandemic which is constantly evolving with many ramifications. 
In the category of what are the effects of other exposures, suicide by railways can be added. In fact there a likely reduction of railway suicides. The other addition could be the impact of working from home, change in workplace etc.

- The authors have righty pointed out that the studies are from newspaper reports, nonrepresentative samples and cross-sectional, hence the generalizability of these findings are limited.

One is not sure of when studies using proxy data like newspaper data are included, and why Google trend studies are not included.

The paper is a call for more robust well-designed studies to understand the association between the pandemic and suicidal behaviour.

Are the rationale for, and objectives of, the Systematic Review clearly stated?

Yes

Are sufficient details of the methods and analysis provided to allow replication by others? Yes

Is the statistical analysis and its interpretation appropriate?

Yes

Are the conclusions drawn adequately supported by the results presented in the review? Yes

Competing Interests: No competing interests were disclosed.

Reviewer Expertise: suicide research

I confirm that I have read this submission and believe that I have an appropriate level of expertise to confirm that it is of an acceptable scientific standard. 
The benefits of publishing with F1000Research:

- Your article is published within days, with no editorial bias

- You can publish traditional articles, null/negative results, case reports, data notes and more

- The peer review process is transparent and collaborative

- Your article is indexed in PubMed after passing peer review

- Dedicated customer support at every stage

For pre-submission enquiries, contact research@f1000.com 